\title{
Stator Vibration Characteristic Identification of Turbogenerator among Single and Composite Faults Composed of Static Air-Gap Eccentricity and Rotor Interturn Short Circuit
}

\author{
Yu-Ling He, ${ }^{1}$ Wei-Qi Deng, ${ }^{1}$ Bo Peng, ${ }^{1}$ Meng-Qiang Ke, ${ }^{1}$ Gui-Ji Tang, \\ Shu-Ting Wan, ${ }^{1}$ and Xiang-Yu Liu ${ }^{2}$ \\ ${ }^{1}$ Department of Mechanical Engineering, North China Electric Power University, Baoding 071003, China \\ ${ }^{2}$ State Grid Hebei Electric Power Research Institute, Shijiazhuang 050021, China \\ Correspondence should be addressed to Yu-Ling He; heyuling1@163.com
}

Received 8 May 2016; Accepted 14 August 2016

Academic Editor: Lu Chen

Copyright (c) 2016 Yu-Ling He et al. This is an open access article distributed under the Creative Commons Attribution License, which permits unrestricted use, distribution, and reproduction in any medium, provided the original work is properly cited.

\begin{abstract}
This paper investigates the radial stator vibration characteristics of turbogenerator under the static air-gap eccentricity (SAGE) fault, the rotor interturn short circuit (RISC) fault, and the composite faults (CFs) composed of SAGE and RISC, respectively. Firstly, the impact of the faulty types on the magnetic flux density (MFD) is analyzed, based on which the detailed expressions of the magnetic pull per unit area (MPPUA) on the stator under different performing conditions are deduced. Then, numerical FEM simulations based on Ansoft and an experimental study are carried out, taking the SDF-9 type fault simulating generator as the study object. It is shown that SAGE will increase the stator vibration at $2 f$ ( $f$ is the electrical frequency) which already exists even in normal condition, while RISC and CF will bring in stator vibrations at $f, 2 f, 3 f$, and $4 f$ at the same time. The vibration amplitudes under $\mathrm{CF}$ are larger than those under RISC. As SAGE increases, the vibration amplitudes of each harmonic component under CF will all be increased, while the development of RISC will decrease the 2nd harmonic vibration but meanwhile increase the 4th harmonic vibration. The achievements of this paper are beneficial for fault identification and condition monitoring of the turbogenerator.
\end{abstract}

\section{Introduction}

SAGE and RISC are common faults of turbogenerator. When the eccentricity degree is more than $10 \%$, severe vibrations, stator core deformations, and even winding damage will be caused [1]. When RISC fault develops progressively, serious consequences, such as field current increment, reactive power output decrease, and bearing vibration aggravation, will be produced. It may also develop into an earth fault and magnetize the rotor. More severely, the shaft journal and the bearing bush may also be burned out [2].

By far, scholars have paid much attention to either SAGE or RISC, while few of them studied the CF considering these two faults occurring at the same time. Achievements obtained for SAGE mainly focus on the three-phase current or voltage change [3-6], the circulating current inside parallel branches (CCPB) and its corresponding diagnosis method [7-9], the unbalanced magnetic pull (UMP) calculation via FEM $[10,11]$, the winding inductance variation based on improved winding function theory [12], and so forth.

For RISC, the primary monitor performances are taken by means of installing extra search coils inside the generator [13]. Meanwhile, the detective methods based on the shaft voltage $[14,15]$ and the CСPB characteristics [16] have also been found as effective tools for this fault. However, the search coil method and the CCPB-based method need to install extra components such as the search coils and the current transformers inside the generator, which is actually not welcomed by the practical performers and needs a higher cost. Relatively, methods based on the stator and rotor vibration characteristics $[17,18]$ and the electromagnetic torque (EMT) [19] are much more convenient due to the easy accomplishment on vibration and EMT data obtaining. The vibrations can be easily obtained by the velocity and acceleration sensors 


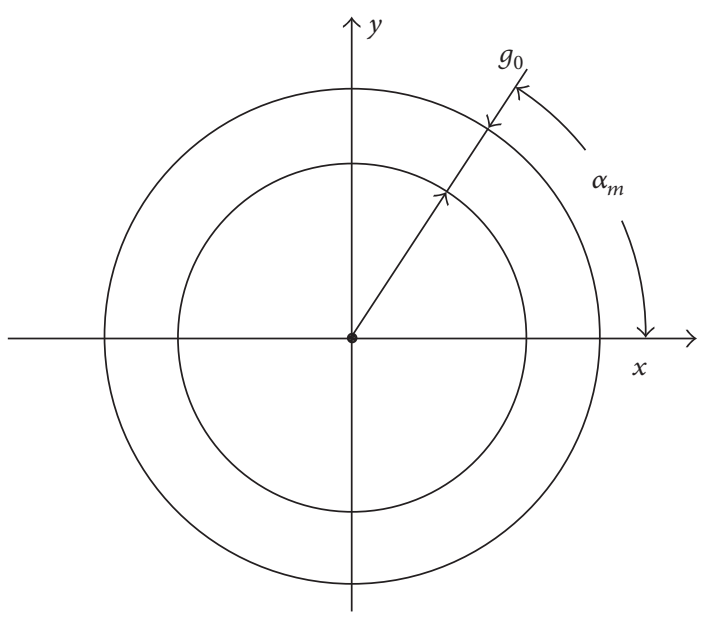

(a) $\operatorname{Normal}\left(\Lambda_{0}=\mu_{0} / g\right)$

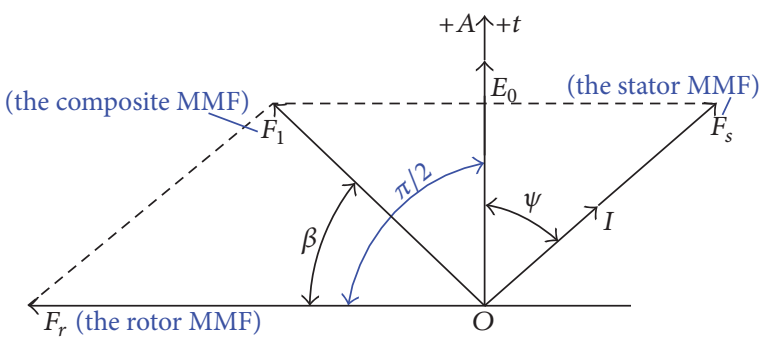

(c) MMF under normal condition and SAGE

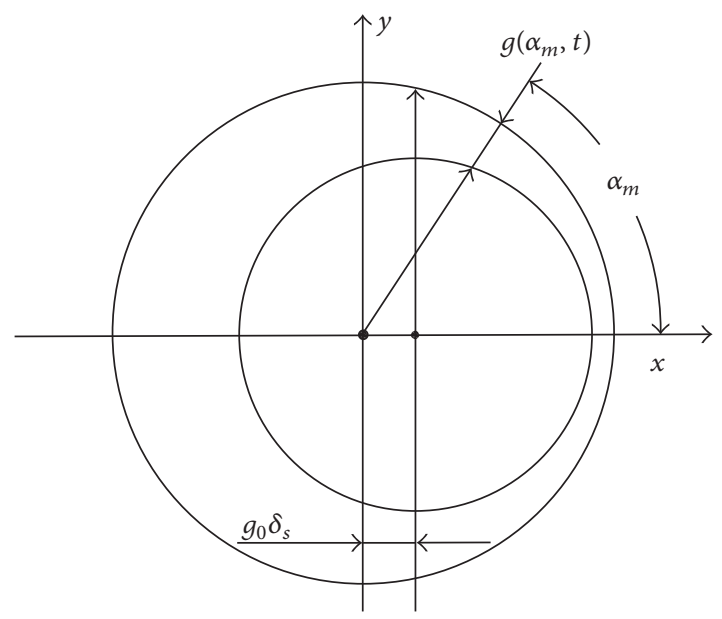

(b) $\operatorname{SAGE}\left(\Lambda\left(\alpha_{m}\right)=\mu_{0} /\left(g_{0}-\delta_{s} \cos \alpha_{m}\right)=\Lambda_{0}+\Lambda_{s} \cos \alpha_{m}\right)$

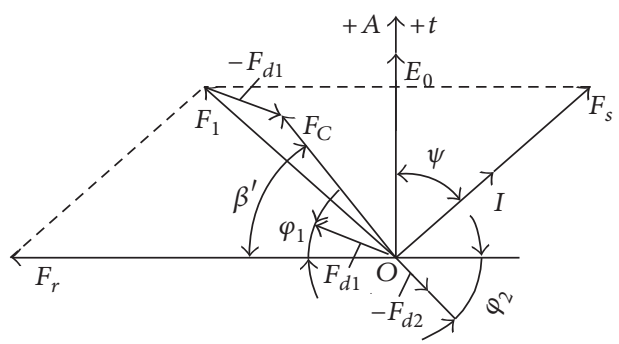

(d) MMF under RISC and CF

FIGURE 1: Air gap and MMFs of turbogenerator under different conditions.

which have usually been already set up inside the generator or by setting sensors outside the generator conveniently, while the EMT can be calculated by using the phase voltages, currents, and the rotating speed of the rotor which can be easily obtained without installing extra sensors [19].

Currently, achievements obtained by scholars have set up a good basis for condition monitoring and diagnosis for these two faults. However, since SAGE exists in almost every generator, there is actually a CF occurring when RISC takes place. Previous studies on this kind of CF found that the failure characteristics are different from those of the single SAGE and RISC faults [20]. Moreover, it has been also found that the rotor vibration has very similar features under many different faults. For example, the mass unbalance of the rotor, the RISC fault, and the stator interturn short circuit (SISC) will all cause rotor vibrations at $f[20-22]$. However, the stator vibration properties are found to be much more distinguishable. The stator will vibrate at $f, 2 f, 3 f$, and $4 f$ under RISC $[20,21]$ and $2 f, 4 f$, and $6 f$ under SISC $[23,24]$, respectively, while under the mass unbalance fault the stator vibration will change very little. Therefore, comparably, the stator vibration has a more sensitive effect to identify the failure types, though most scholars have paid their primary attention to the rotor vibrations but not the stator vibration characteristics $[18,20-$ 22, 24].

As an improvement, this paper investigates the stator vibration characteristics under SAGE, RISC, and CF composed of SAGE and RISC, respectively, in order to obtain a significant identification criterion for these three faults. The whole work is taken based on the theoretical analysis, the numerical FEM simulation, and the experiment study.

\section{Theoretical Analysis}

2.1. Magnetic Flux Density. The air-gap magnetic flux density (MFD) is composed of the magnetomotive force (MMF) and the permeance per unit area (PPUA) through a multiplying operation. Generally, RISC mainly affects MMF, while SAGE primarily affects PPUA. Thus, MFD will be affected by either of these two faults. Typically, the air gap and MMFs under different conditions are indicated in Figure 1 [20].

PPUAs and MMFs for each case can be written as

$$
\Lambda_{\text {Normal }}\left(\alpha_{m}, t\right)=\frac{\mu_{0}}{g_{0}}=\Lambda_{0}
$$

(Normal condition, RISC),

$$
\begin{aligned}
\Lambda_{\mathrm{SGE}}\left(\alpha_{m}, t\right) & =\frac{\mu_{0}}{g\left(\alpha_{m}, t\right)}=\frac{\mu_{0}}{g_{0}\left(1-\delta_{s} \cos \alpha_{m}\right)} \\
& \approx \Lambda_{0}\left(1+\delta_{s} \cos \alpha_{m}\right) \\
& =\Lambda_{0}+\Lambda_{s} \cos \alpha_{m} \quad \text { (SAGE, CF) }
\end{aligned}
$$




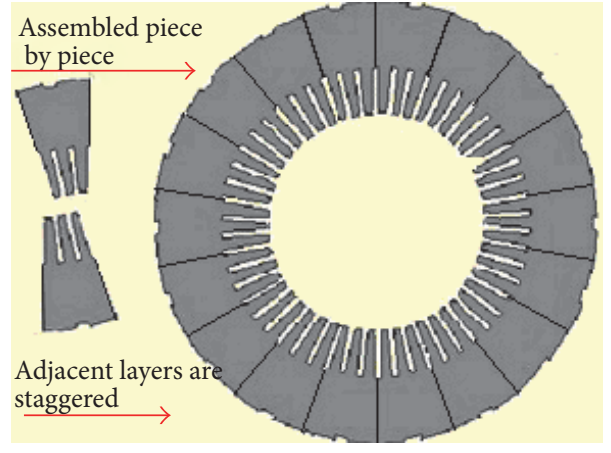

(a) Structure of stator core

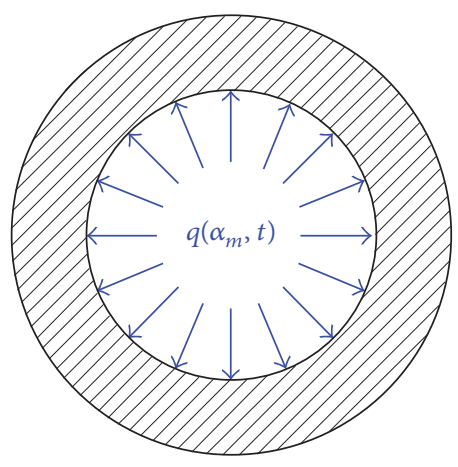

(b) MPPUA on stator core

FIgURE 2: Structure and magnetic force of stator core.

$$
\begin{aligned}
f_{\text {Normal }}\left(\alpha_{m}, t\right)= & F_{s} \cos \left(\omega t-\alpha_{m}-\psi-0.5 \pi\right) \\
& +F_{r} \cos \left(\omega t-\alpha_{m}\right) \\
= & F_{1} \cos \left(\omega t-\alpha_{m}-\beta\right)
\end{aligned}
$$

(Normal condition, SAGE),

$$
\begin{aligned}
f_{\mathrm{RISC}}\left(\alpha_{m}, t\right)= & F_{1} \cos \left(\omega t-\alpha_{m}-\beta\right) \\
& -F_{d 1} \cos \left(\omega t-\alpha_{m}-\varphi_{1}\right) \\
& -F_{d 2} \cos 2\left(\omega t-\alpha_{m}-\pi-\varphi_{2}\right) \\
= & F_{C} \cos \left(\omega t-\alpha_{m}-\beta^{\prime}\right) \\
& -F_{d 2} \cos \left(2 \omega t-\alpha_{m}-\pi-\varphi_{2}\right)
\end{aligned}
$$

(RISC, CF),

where

$$
\begin{aligned}
& F_{1}=\sqrt{\left(F_{r}-F_{s} \sin \psi\right)^{2}+\left(F_{s} \cos \psi\right)^{2}}, \\
& \beta=\arctan \frac{F_{s} \cos \psi}{F_{r}-F_{s} \sin \psi}, \\
& F_{C} \\
& =\sqrt{\left(F_{r}-F_{s} \sin \psi-F_{d 1} \cos \varphi_{1}\right)^{2}+\left(F_{s} \cos \psi-F_{d 1} \sin \varphi_{1}\right)^{2}}, \\
& \beta^{\prime}=\arctan \frac{F_{s} \cos \psi-F_{d 1} \sin \varphi_{1}}{F_{r}-F_{s} \sin \psi-F_{d 1} \cos \varphi_{1}} .
\end{aligned}
$$

Correspondingly, MFDs under different conditions are

$$
B\left(\alpha_{m}, t\right)=F_{1} \Lambda_{0} \cos \left(\omega t-\alpha_{m}-\beta\right)
$$

(Normal condition),

$$
B\left(\alpha_{m}, t\right)=F_{1}\left(\Lambda_{0}+\Lambda_{s} \cos \alpha_{m}\right) \cos \left(\omega t-\alpha_{m}-\beta\right)
$$

$$
\begin{aligned}
& B\left(\alpha_{m}, t\right)=\left[F_{C} \cos \left(\omega t-\alpha_{m}-\beta^{\prime}\right)\right. \\
& \left.\quad-F_{d 2} \cos 2\left(\omega t-\alpha_{m}-\pi-\varphi_{2}\right)\right] \Lambda_{0} \quad \text { (RISC) }
\end{aligned}
$$

$$
\begin{array}{r}
B\left(\alpha_{m}, t\right)=\left(\Lambda_{0}+\Lambda_{s} \cos \alpha_{m}\right) F_{C} \cos \left(\omega t-\alpha_{m}-\beta^{\prime}\right) \\
-\left(\Lambda_{0}+\Lambda_{s} \cos \alpha_{m}\right) F_{d 2} \cos 2\left(\omega t-\pi-\alpha_{m}-\varphi_{2}\right)
\end{array}
$$

where $F_{1}$ and $F_{C}$ are the composite MMFs of 1st harmonic under normal condition and $\mathrm{CF}$, respectively $\left(F_{1}>F_{C}\right) . F_{r}$ and $F_{s}$ are, respectively, the rotor MMF and the stator MMF at the fundamental frequency. $F_{d 1}$ and $F_{d 2}$ are the reverse MMFs of 1 st and 2 nd harmonic produced by RISC. $\Lambda_{0}$ is the constant component of PPUA, while $\Lambda_{s}=\Lambda_{0} \delta_{s}$ is the component caused by the SAGE. $\alpha_{m}$ is a mechanical angle to indicate the circumferential position of the air gap.

As indicated in (4a)-(4d), MFDs under normal condition and SAGE are mainly composed of 1st harmonic components, with the amplitudes of $F_{1} \Lambda_{0}$ and $F_{1}\left(\Lambda_{0}+\Lambda_{s} \cos \alpha_{m}\right)$, respectively. Actually, the occurrence of SAGE will generally increase the permeance, because the full expansion of the power series (the second formula in (1)) is $\Lambda_{0}\left(1+\Lambda_{s} \cos \alpha_{m}+\right.$ $\left.0.5 \Lambda_{s}^{2}+0.5 \cos 2 \alpha_{m}+\cdots\right)$, which is obviously larger than the normal permeance $\Lambda_{0}$. Consequently, as SAGE is increased, the faulty MFD amplitude will be enlarged.

However, in the cases of RISC and CF, besides the 1st harmonic components, 2nd harmonic components also exist. As RISC develops, the inverse MMFs of 1st harmonic and 2nd harmonic will both be increased, resulting in the decrease of the 1st MFD but meanwhile the increment of the 2nd MFD (see Figure 1(d)).

\subsection{Exciting Characteristics of MPPUA}

2.2.1. Stator Structure and Essential Exciting Force. The generator stator is made up of the stator core, the windings, the frame, the end covers, and so forth. Stator vibrations are primarily produced by the magnetic forces acting on the stator core. This kind of magnetic force is actually a unit magnetic pull performing on the whole inner surface of the stator core, usually called magnetic pull per unit area (MPPUA), as indicated in Figure 2. Since the structure of the stator core is similar to a hollow shell, its radial rigidity is small. Even if the resultant force of MPPUA over the whole inner face is zero, the stator core will still have a periodic shrinking-expanding 
deformation under the excitation of the pulsating MPPUA. Typically, this periodic shrinking-expanding deformation is actually the radial vibration, which has been well known by people.

MPPUA mainly acts on the stator core surface, and the composite magnetic pulls can be obtained by integrating MPPUA. Because the stator core is a shell structure that is made up of silicon steel sheets, the radial rigidity is small and the composite magnetic pull is zero (shown in Figure 2). However, under the periodic MPPUA, the stator core also can generate the radial vibration, such as the periodic expansioncontraction. Therefore, MPPUA is the nature exciting force of stator vibration.

Therefore, due to the specific structure of the stator core, the essential exciting force for the stator vibration is MPPUA, which can be deduced based on

$$
q\left(\alpha_{m}, t\right)=\frac{B^{2}\left(\alpha_{m}, t\right)}{2 \mu_{0}}
$$

2.2.2. Exciting Characteristics of MPPUA. Substituting (4a)(4d) into (5), the MPPUA expressions, respectively, under normal condition, SAGE, RISC, and CF can be obtained:

$$
\begin{aligned}
& q\left(\alpha_{m}, t\right)=\frac{F_{1}^{2} \Lambda_{0}^{2}}{4 \mu_{0}}\left[1+\cos \left(2 \omega t-2 \alpha_{m}-2 \beta\right)\right] \\
& \text { (Normal condition), } \\
& q\left(\alpha_{m}, t\right)=\frac{F_{1}^{2}}{8 \mu_{0}}\left[\left(2 \Lambda_{0}^{2}+\Lambda_{s}^{2}\right)+\left(4 \Lambda_{0} \Lambda_{s} \cos \alpha_{m}\right)\right. \\
& +\left(\Lambda_{s}^{2} \cos 2 \alpha_{m}\right)+0.5 \Lambda_{s}^{2} \cos (2 \omega t-2 \beta)+2 \Lambda_{0} \Lambda_{s} \\
& \cdot \cos \left(2 \omega t-\alpha_{m}-2 \beta\right)+\left(2 \Lambda_{0}^{2}+\Lambda_{s}^{2}\right) \\
& \cdot \cos \left(2 \omega t-2 \alpha_{m}-2 \beta\right)+2 \Lambda_{0} \Lambda_{s} \\
& \cdot \cos \left(2 \omega t-3 \alpha_{m}-2 \beta\right)+0.5 \Lambda_{s}^{2} \\
& \left.\cdot \cos \left(2 \omega t-4 \alpha_{m}-2 \beta\right)\right] \quad(\mathrm{SAGE}), \\
& q\left(\alpha_{m}, t\right)=\frac{\Lambda_{0}^{2}}{4 \mu_{0}}\left[F_{C}^{2}+F_{d 2}^{2}-2 F_{C} F_{d 2}\right. \\
& \cdot \cos \left(\omega t-\alpha_{m}+\beta_{1}-2 \varphi_{2}\right)+F_{C}^{2} \\
& \cdot \cos 2\left(\omega t-\alpha_{m}-\beta\right)-2 F_{C} F_{d 2} \\
& \cdot \cos \left(3 \omega t-3 \alpha_{m}-\beta_{1}-2 \varphi_{2}\right)+F_{d 2}^{2} \\
& \left.\cdot \cos 4\left(\omega t-\alpha_{m}-\varphi_{2}\right)\right] \quad(\text { RISC) }, \\
& q\left(\alpha_{m}, t\right)=\frac{1}{8 \mu_{0}}\left\{\left[\left(F_{C}^{2}+F_{d 2}^{2}\right)\left(2 \Lambda_{0}^{2}+\Lambda_{s}^{2}\right)\right.\right. \\
& +4\left(F_{C}^{2}+F_{d 2}^{2}\right) \Lambda_{0} \Lambda_{s} \cos \alpha_{m} \\
& \left.+\left(F_{C}^{2}+F_{d 2}^{2}\right) \Lambda_{s}^{2} \cos 2 \alpha_{m}\right]
\end{aligned}
$$

$$
\begin{aligned}
& +F_{C} F_{d 2}\left[-4 \Lambda_{0} \Lambda_{s} \cos \left(\omega t+\beta_{1}-2 \varphi_{2}\right)\right. \\
& -2\left(2 \Lambda_{0}^{2}+\Lambda_{s}^{2}\right) \cos \left(\omega t-\alpha_{m}+\beta_{1}-2 \varphi_{2}\right) \\
& -\Lambda_{s}^{2} \cos \left(\omega t+\alpha_{m}+\beta_{1}-2 \varphi_{2}\right) \\
& -4 \Lambda_{0} \Lambda_{s} \cos \left(\omega t-2 \alpha_{m}+\beta_{1}-2 \varphi_{2}\right) \\
& \left.-\Lambda_{s}^{2} \cos \left(\omega t-3 \alpha_{m}+\beta_{1}-2 \varphi_{2}\right)\right] \\
& +F_{C}^{2}\left[0.5 \Lambda_{s}^{2} \cos \left(2 \omega t-2 \beta_{1}\right)\right. \\
& +2 \Lambda_{0} \Lambda_{s} \cos \left(2 \omega t-\alpha_{m}-2 \beta_{1}\right) \\
& +\left(2 \Lambda_{0}^{2}+\Lambda_{s}^{2}\right) \cos \left(2 \omega t-2 \alpha_{m}-2 \beta_{1}\right) \\
& +2 \Lambda_{0} \Lambda_{s} \cos \left(2 \omega t-3 \alpha_{m}-2 \beta_{1}\right) \\
& \left.+0.5 \Lambda_{s}^{2} \cos \left(2 \omega t-4 \alpha_{m}-2 \beta_{1}\right)\right] \\
& +F_{C} F_{d 2}\left[-\Lambda_{s}^{2} \cos \left(3 \omega t-\alpha_{m}-\beta_{1}-2 \varphi_{2}\right)\right. \\
& -4 \Lambda_{0} \Lambda_{s} \cos \left(3 \omega t-2 \alpha_{m}-\beta_{1}-2 \varphi_{2}\right) \\
& -2\left(2 \Lambda_{0}^{2}+\Lambda_{s}^{2}\right) \cos \left(3 \omega t-3 \alpha_{m}-\beta_{1}-2 \varphi_{2}\right) \\
& -4 \Lambda_{0} \Lambda_{s} \cos \left(3 \omega t-4 \alpha_{m}-\beta_{1}-2 \varphi_{2}\right) \\
& \left.-\Lambda_{s}^{2} \cos \left(3 \omega t-5 \alpha_{m}-\beta_{1}-2 \varphi_{2}\right)\right] \\
& +F_{d 2}^{2}\left[0.5 \Lambda_{s}^{2} \cos \left(4 \omega t-2 \alpha_{m}-4 \varphi_{2}\right)\right. \\
& +2 \Lambda_{0} \Lambda_{s} \cos \left(4 \omega t-3 \alpha_{m}-4 \varphi_{2}\right) \\
& +\left(2 \Lambda_{0}^{2}+\Lambda_{s}^{2}\right) \cos \left(4 \omega t-4 \alpha_{m}-4 \varphi_{2}\right) \\
& +2 \Lambda_{0} \Lambda_{s} \cos \left(4 \omega t-5 \alpha_{m}-4 \varphi_{2}\right) \\
& \left.\left.+0.5 \Lambda_{s}^{2} \cos \left(4 \omega t-6 \alpha_{m}-4 \varphi_{2}\right)\right]\right\} \quad(\mathrm{CF})
\end{aligned}
$$

As indicated in (6a)-(6d), MPPUA has different pulsating components under different performing conditions. Since the stator vibration is actually the response of the exciting MPPUA, the vibration spectrum should have the same harmonic components as MPPUA. Obviously, under normal condition and SAGE, the stator vibration has only 2 nd harmonic components (the DC component force will not bring in vibrations to the stator but will induce a radial deformation tendency after a long action). The occurrence of SAGE will increase the vibration amplitude at $2 f$. However, when RISC or CF takes place, besides the 2nd harmonic components, 1st, $3 \mathrm{rd}$, and 4th harmonic components will also be produced. To further study the exciting characteristics of MPPUA and the stator vibration response features, the upper amplitude expressions of each MPPUA component under different conditions are shown in Table 1 , where $I_{f}$ is the exciting current of the generator, $f_{\text {sd }}$ is the shorted degree of RISC, and $\delta_{s}$ is the relative SAGE value. 
TABLE 1: Upper amplitude expressions of MPPUA for different conditions.

\begin{tabular}{|c|c|c|c|}
\hline Component & Performing condition & Amplitude formulas & Influential factors \\
\hline \multirow{4}{*}{ DC component } & Normal condition & $F_{1}^{2} \Lambda_{0}^{2} / 4 \mu_{0}$ & $I_{f}$ \\
\hline & SAGE & $F_{1}^{2}\left(\Lambda_{0}+\Lambda_{s}\right)^{2} / 4 \mu_{0}$ & $I_{f}, \delta_{s}$ \\
\hline & RISC & $\left(F_{C}^{2}+F_{d 2}^{2}\right) \Lambda_{0}^{2} / 4 \mu_{0}$ & $I_{f}, f_{\mathrm{sd}}$ \\
\hline & $\mathrm{CF}$ & $\left(F_{C}^{2}+F_{d 2}^{2}\right)\left(\Lambda_{0}+\Lambda_{s}\right)^{2} / 4 \mu_{0}$ & $I_{f}, \delta_{s}, f_{\mathrm{sd}}$ \\
\hline \multirow{4}{*}{ 1st harmonic } & Normal condition & - & - \\
\hline & SAGE & - & - \\
\hline & RISC & $-F_{C} F_{d 2} \Lambda_{0}^{2} / 2 \mu_{0}$ & $I_{f}, f_{\mathrm{sd}}$ \\
\hline & $\mathrm{CF}$ & $F_{C} F_{d 2}\left(\Lambda_{0}+\Lambda_{s}\right)^{2} / 2 \mu_{0}$ & $I_{f}, \delta_{s}, f_{\mathrm{sd}}$ \\
\hline \multirow{4}{*}{ 2nd harmonic } & Normal condition & $F_{1}^{2} \Lambda_{0}^{2} / 4 \mu_{0}$ & $I_{f}$ \\
\hline & SAGE & $F_{1}^{2}\left(\Lambda_{0}+\Lambda_{s}\right)^{2} / 4 \mu_{0}$ & $I_{f}, \delta_{s}$ \\
\hline & RISC & $F_{C}^{2} \Lambda_{0}^{2} / 4 \mu_{0}$ & $I_{f}, f_{\text {sd }}$ \\
\hline & $\mathrm{CF}$ & $F_{C}^{2}\left(\Lambda_{0}+\Lambda_{s}\right)^{2} / 4 \mu_{0}$ & $I_{f}, \delta_{s}, f_{\mathrm{sd}}$ \\
\hline \multirow{4}{*}{ 3rd harmonic } & Normal condition & - & - \\
\hline & SAGE & - & - \\
\hline & RISC & $-F_{C} F_{d 2} \Lambda_{0}^{2} / 2 \mu_{0}$ & $I_{f}, f_{\mathrm{sd}}$ \\
\hline & $\mathrm{CF}$ & $F_{C} F_{d 2}\left(\Lambda_{0}+\Lambda_{s}\right)^{2} / 2 \mu_{0}$ & $I_{f}, \delta_{s}, f_{\mathrm{sd}}$ \\
\hline \multirow{4}{*}{ 4th harmonic } & Normal condition & - & - \\
\hline & SAGE & - & - \\
\hline & RISC & $F_{d 2}^{2} \Lambda_{0}^{2} / 4 \mu_{0}$ & $I_{f}, f_{\mathrm{sd}}$ \\
\hline & $\mathrm{CF}$ & $F_{d 2}^{2}\left(\Lambda_{0}+\Lambda_{s}\right)^{2} / 4 \mu_{0}$ & $I_{f}, \delta_{s}, f_{\mathrm{sd}}$ \\
\hline
\end{tabular}

As shown in Table 1, SAGE has larger MPPUA magnitude at $2 f$, while RISC has smaller MPPUA magnitude at $2 f$ than normal condition. Specifically, CF has larger MPPUA amplitudes at $f, 2 f, 3 f$, and $4 f$ than RISC. Consequently, the occurrence of SAGE will increase the 2nd harmonic vibration of stator, while RISC will decrease the 2nd harmonic vibration amplitude. The stator vibration amplitudes at $f, 2 f, 3 f$, and $4 f$ under CF condition will be more intense than under RISC condition. This can be used for the fault identification among the single and the composite faults composed of SAGE and RISC.

\section{Numerical Simulation and Experiment Study}

3.1. Object and Method. The numerical FEM simulation and the experiment study are taken for a SDF-9 type nonsalient pole fault simulating generator (see Figure 3(a)) in the State Key Lab of New Energy and Electric Power System, China, whose primary parameters are indicated in Table 2.

The rotor of the generator is fixed by the bearing block, while the stator can be moved along the horizontally radial direction by adjusting the four screws on the generator to simulate SAGE faults. The movement performance can be controlled by the two dial indicators, as shown in Figure 3(b). Outside the generator, there is a plate with shorted taps of the exciting windings, as indicated in Figure 3(c). RISC can be simulated by connecting different taps. Also, CF conditions with different faulty degrees can be applied via setting different SAGE values and connecting different taps at the same time. During the experiment, the exciting current is set to
TABLE 2: Primary parameters of SDF-9 type generator.

\begin{tabular}{lc}
\hline Parameter & Value \\
\hline Rated capacity & $7.5 \mathrm{kVA}$ \\
Rated voltage & $400 \mathrm{~V}$ \\
Power factor & 0.8 \\
Rated speed & $n_{r}=3000 \mathrm{rpm}$ \\
Number of pole pairs & $p=1$ \\
Radial air-gap length & $g_{0}=0.8 \mathrm{~mm}$ \\
Stator series conductors per phase & $N_{s}=100$ \\
Axial length & $L_{0}=100 \mathrm{~mm}$ \\
Number of stator slots & $Z_{1}=24$ \\
Ratio of pitch to polar distance & $K_{y}=y / \tau=0.83$ \\
Pitch-shortening value & $k_{p}=0.966$ \\
Distribution coefficient & $k_{d}=0.958$ \\
Number of parallel branches & $\alpha=2$ \\
Number of exciting turns for each pole & $N_{f}=480$ \\
\hline
\end{tabular}

$0.8 \mathrm{~A}$, the rotating speed of the rotor is set to $3000 \mathrm{rpm}$ (the rotary period is $20 \mathrm{~ms}$ and the frequency is $50 \mathrm{~Hz}$ ), and the line voltage is $380 \mathrm{~V}$. The experimental testing system is indicated in Figure 3(d).

Objectively, there are some differences to set the velocity sensors in different positions. The general rigidities in the horizontal direction and the vertical direction are different (the vertical direction has a larger rigidity because the foundation is in this direction and therefore sensors here will sample smaller vibration amplitudes). What is more, since 


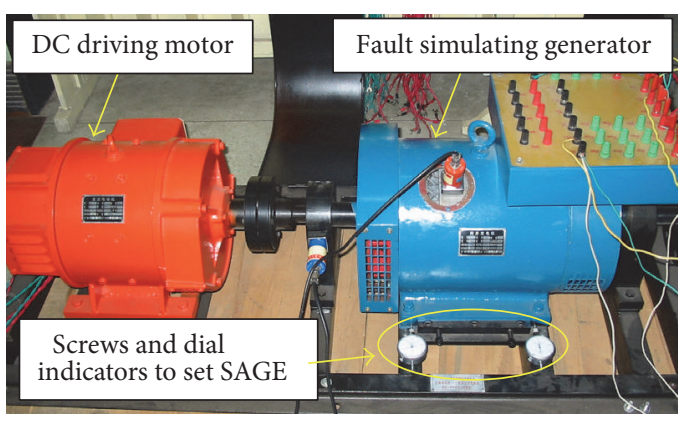

(a) Physical model of SDF-9 type generator

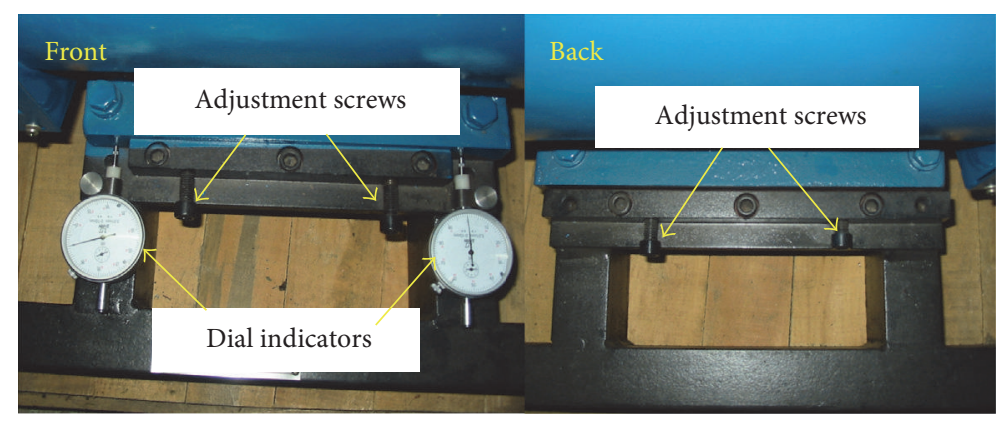

(b) Method to set SAGE

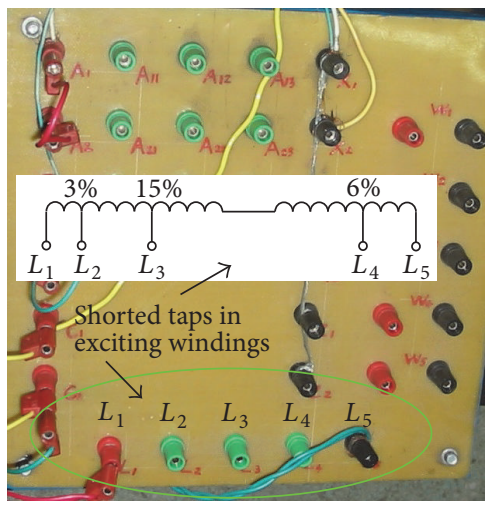

(c) Method to set RISC

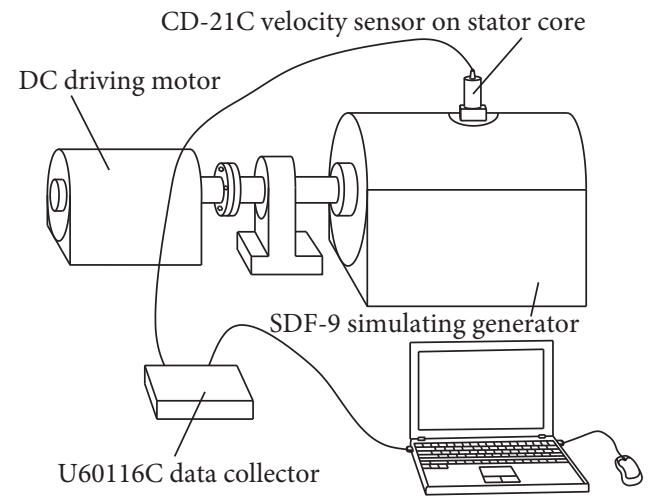

(d) Experimental testing system

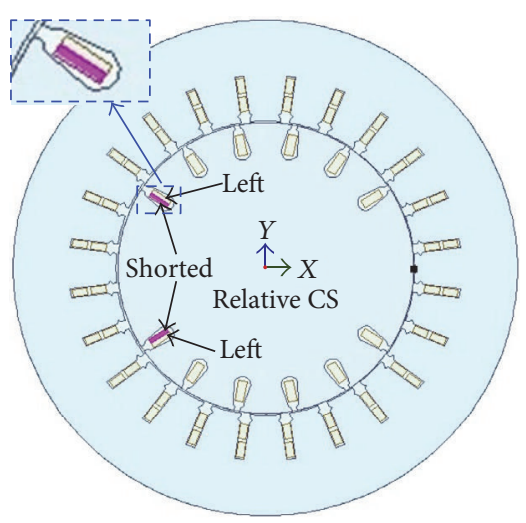

(e) 2D finite element model

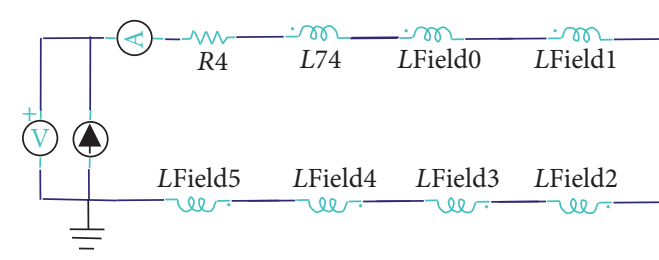

(f) Coupling circuit of rotor winding for normal and SAGE cases

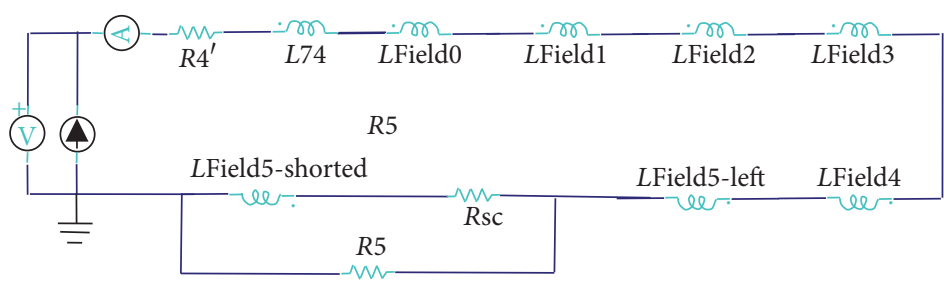

(g) Coupling circuit of rotor winding for RISC and CF

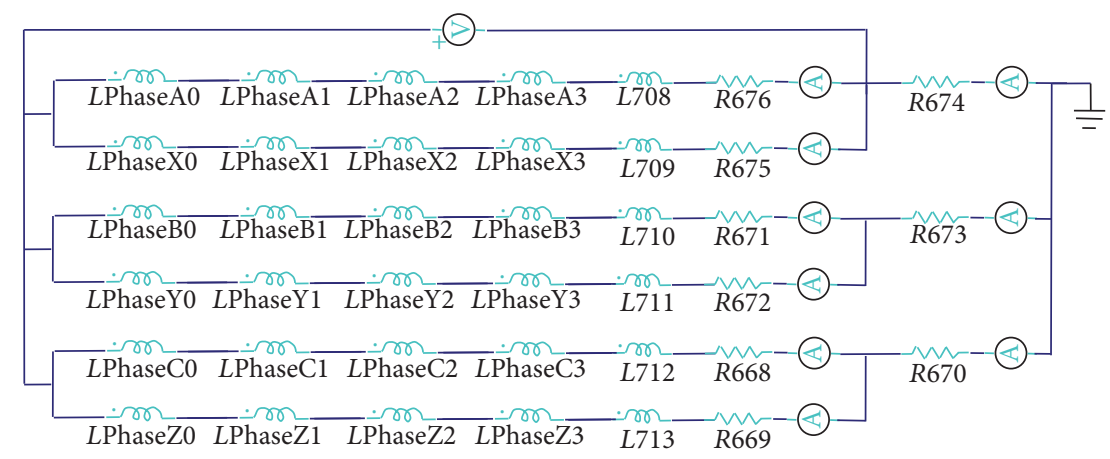

(h) Coupling circuit for stator windings

FIGURE 3: Study object of SDF-9 type generator.

the stator is moved along the horizontal direction, the magnetic flux density is larger on one side in this direction but smaller on the other side. So, the MPPUA density is actually larger on the side which has the minimum air-gap length but smaller on the opposite side. Consequently, the sensors set on different positions will have varied vibration amplitudes.
However, no matter where the sensors are set, the developing tendency of the stator vibration will be the same due to the uniform exciting force indicated in (6a)-(6d).

The finite element model is built up, setting the performing parameters the same as the experiment, as indicated in Figure 3(e). The corresponding external coupling circuits for 
the exciting windings and the stator windings are illustrated in Figures 3(f), 3(g), and 3(h).

The experiment work and the FEM simulation study are gradually taken by following the four steps.

(1) Normal Performance. The generator performs in normal condition without setting SAGE or RISC, and the stator vibration data is collected as a comparing reference. In addition, the MPPUA in normal condition on the stator is also calculated through the FEM simulation.

(2) SAGE Cases. $0.1 \mathrm{~mm}(12.5 \%), 0.2 \mathrm{~mm}(25 \%)$, and $0.3 \mathrm{~mm}$ (37.5\%) SAGEs are set each time, respectively, both in the experiment performance and in the FEM simulation. For the simulation, the rotor and the exciting windings are shifted along the $x$-axis to simulate different SAGE conditions (see Figure 3(e)). Experimental stator vibration signals and calculated MPPUA data are collected for further study.

(3) RISC Cases. 3\%, 6\%, and 12\% RISC are, respectively, set in the experiments by connecting $L_{1} L_{2}, L_{4} L_{5}$, and $L_{2} L_{3}$. Also, the same RISC degrees are set in the FEM simulation by adjusting the values of $L_{\text {Field5-shorted }}$ and $L_{\text {Field5-left }}$ indicated in Figure $3(\mathrm{~g})$. Correspondingly, the conductors in the shorted slot of the FEM model are divided into two parts. One is the shorted part, and the other is the left part, as indicated in Figure 3(e).

(4) CF Cases. Firstly, $0.1 \mathrm{~mm}$ SAGE is set up, and 3\%, 6\%, and $12 \%$ RISC are set each time, respectively, both in the experiments and in the simulations. Secondly, 3\% RISC is set up, and $0.1 \mathrm{~mm}, 0.3 \mathrm{~mm}$, and $0.5 \mathrm{~mm}$ SAGE conditions are applied each time, respectively. By doing this, the impacts of SAGE and the effects of RISC on MPPUA and the stator vibrations under $\mathrm{CF}$ conditions can be obtained.

\subsection{Results and Discussion}

3.2.1. Pass-Band Results. MPPUA distributions on stator under different performing conditions obtained by FEM calculation are indicated in Figure 4. It is shown that the district near the pole has a much more intense MPPUA, while at other positions MPPUA has a very little value. This is because the magnetic lines near the poles have the strongest intensity. In normal condition, the MPPUA distribution is of symmetry, while the occurrence of SAGE, RISC, or CF will break this symmetry. As SAGE increases, MPPUA will be increased, as indicated in Figures 4(a)-4(d). It is also indicated that the very place which has the largest MPPUA is generally in accordance with the position where the radial air-gap length is the minimum. This is caused due to the max permeance in this position; see (1) and Figure 1(b).

However, when RISC takes place, MPPUA will be decreased, as indicated in Figures 4(a) and 4(e). This is because RISC decreases the effective exciting ampere turns. This can be also explained by comparing Figure 1(c) with Figure 1(d). The primary MMF $F_{C}$ under RISC (see Figure $1(\mathrm{~d})$ ) is actually smaller than $F_{1}$ in normal condition (see Figure 1(c)) due to the effect of the induced inverse MMF $F_{d 1}$. The more serious RISC is, the more MPPUA will be decreased, as indicated in Figures $4(\mathrm{e})-4(\mathrm{~g})$.

Comparing Figure 4(h) with Figures 4(b) and 4(e), it is obvious that MPPUA under CF is smaller than that under SAGE but meanwhile larger than that under RISC. Besides, as SAGE increases, MPPUA under CF will also be increased, as indicated in Figures $4(\mathrm{~h}), 4(\mathrm{k})$, and $4(\mathrm{l})$. However, the development of RISC will decrease MPPUA in general, as illustrated in Figures $1(\mathrm{~h})-1(\mathrm{j})$. This means RISC will generally decrease MFD while SAGE will generally increase MFD, which follows the previous theoretical analysis in Section 2.1.

To show the developing tendency of MPPUA more clearly, the time domain curves for a stable period obtained from FEM calculations for each performing condition are indicated in Figure 5. It is shown that, under the single SAGE fault, the increment of SAGE will raise the value of MPPUA, as shown in Figure 5(a). On the contrary, the occurrence and the development of RISC will generally bring down the value of MPPUA (the mean value and the RMS value are both decreased), as indicated in Figure 5(b).

For the CF cases, the increment of SAGE will increase MPPUA (see Figure 5(c)), while the development of RISC will decrease MPPUA (see Figure 5(d)). This developing trend is in accordance with the single faults. Comparatively, MPPUA under CF is larger than that under the single RISC fault, as indicated in Figure 5(c). However, MPPUA under CF is smaller than that under the single SAGE fault, as illustrated in Figure 5(d). This also means that SAGE will generally increase MFD while RISC will primarily decrease MFD, which again confirms the theoretical analysis in Section 2.1.

Correspondingly, the stator vibration intensity, which is computed via (7), is shown in Figure 6. In (7), $y_{i}$ is the vibration speed, $m$ is the total number of sampling points, and $y$ is the vibration intensity. Hence,

$$
y=\sqrt{\frac{\sum_{i=1}^{m} y_{i}^{2}}{m} .}
$$

As indicated in Figure 6, it is clear that whether under the single SAGE fault or CF, the increment of SAGE will increase the stator vibration intensity. However, the development of RISC will decrease the stator vibration intensity. In addition, it is also suggested from Figure 6 that the vibration intensity under CF is smaller than that under the single SAGE fault but meanwhile larger than that under the single RISC fault. This is in accordance with the qualitative result obtained in the theoretical analysis and the MPPUA data presented above.

3.2.2. Special-Frequency Component Results. To further study the impact of different faulty kinds on the stator vibration characteristics, special-frequency components of MPPUA and vibration, including the 1st, 2nd, 3rd, and 4th harmonic components, are investigated as well. The MPPUA amplitudes for each harmonic component under different performing conditions are indicated in Figure 7, while the stator vibration spectra are shown in Figure 8.

It is suggested from Figure 7(a) that, in normal condition, MPPUA mainly has a DC component and a 2nd harmonic component, which well follows the theoretical result 


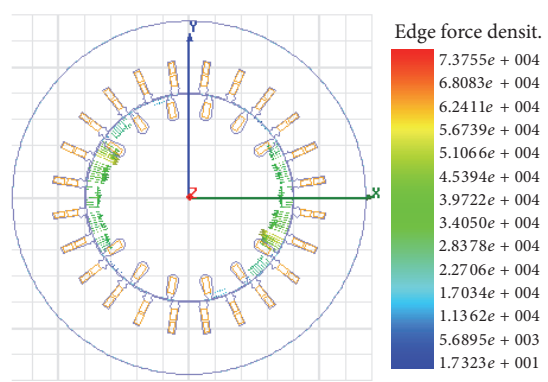

(a) Normal condition

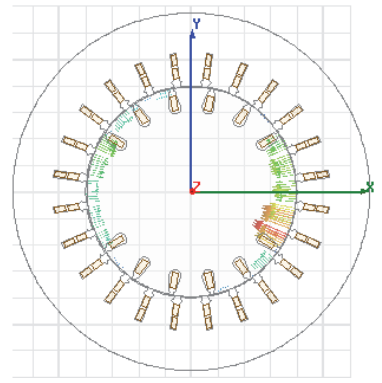

(d) $0.3 \mathrm{~mm}$ SAGE

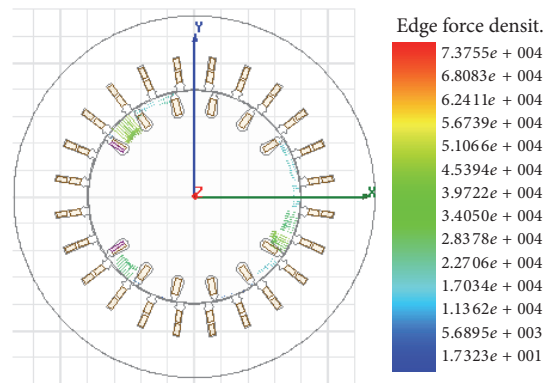

(g) $12 \%$ RISC

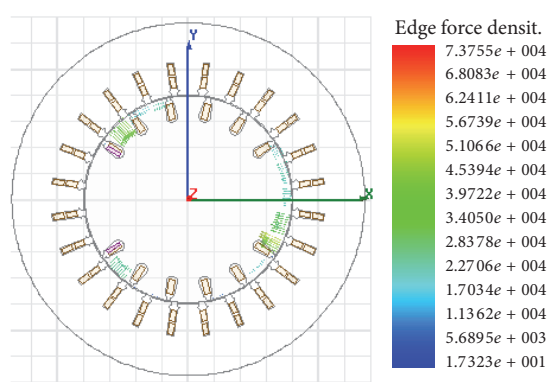

(j) $0.1 \mathrm{~mm}$ SAGE and $12 \%$ RISC

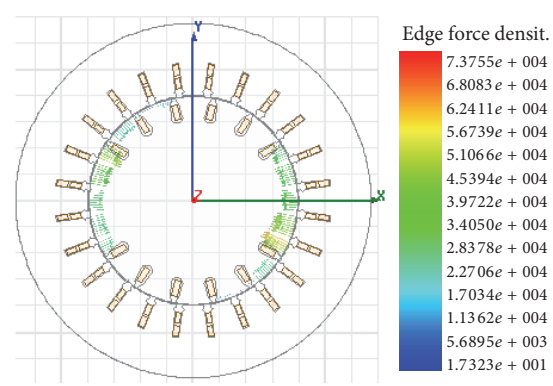

(b) $0.1 \mathrm{~mm}$ SAGE

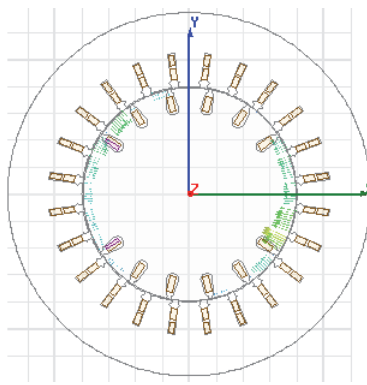

(e) $3 \%$ RISC

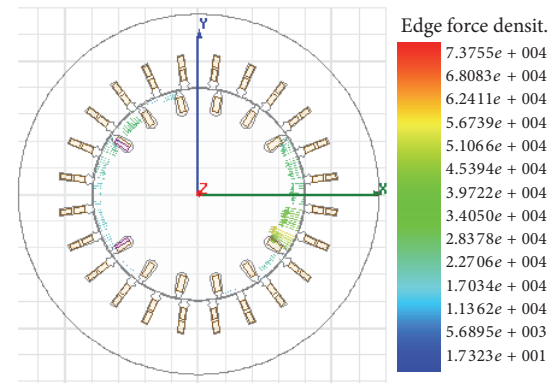

(h) $0.1 \mathrm{~mm}$ SAGE and $3 \%$ RISC

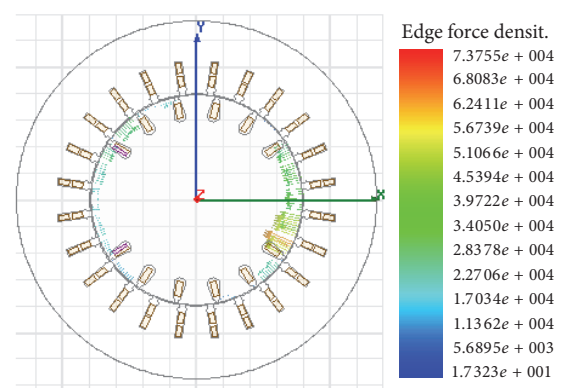

(k) $0.2 \mathrm{~mm}$ SAGE and $3 \%$ RISC

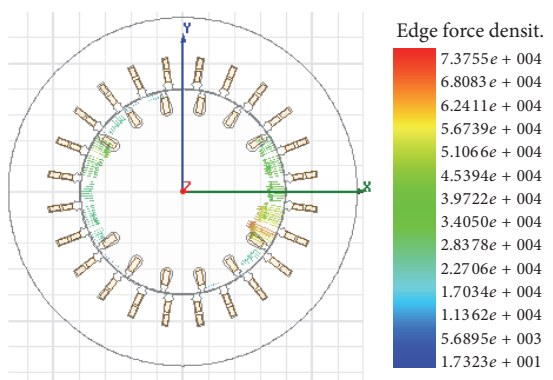

(c) $0.2 \mathrm{~mm} \mathrm{SAGE}$

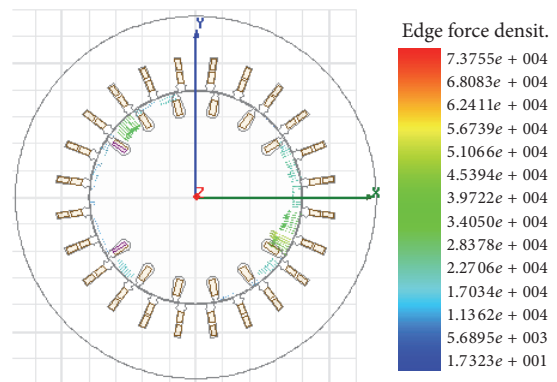

(f) $6 \%$ RISC

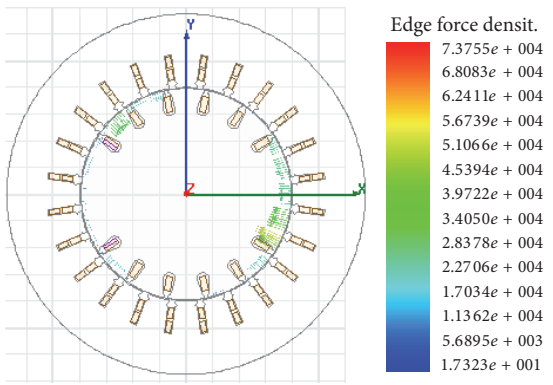

(i) $0.1 \mathrm{~mm}$ SAGE and $6 \%$ RISC

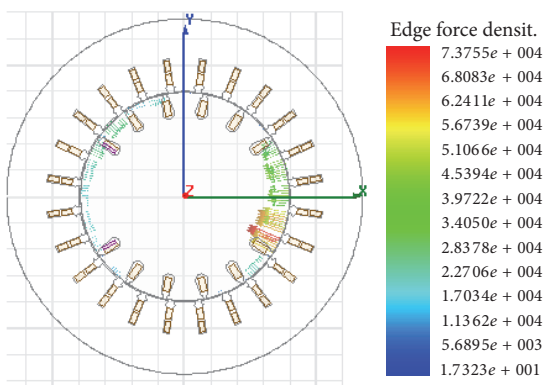

(l) $0.3 \mathrm{~mm}$ SAGE and $3 \%$ RISC

FIGURE 4: MPPUA distribution under different conditions.

indicated in (6a)-(6d). Actually, there is still a tiny 4th harmonic component. The very reason for this extra 4 th harmonic component is because MPPUA is the square result of MFD (see (5)) which has not only the fundamental-frequency component but also the other odd harmonics. Consequently, MPPUA should theoretically have each even harmonic component due to the square operation, with the even harmonic components' amplitudes decreased as the harmonic order increases. Equations (6a)-(6d) only consider the 1st harmonic but ignore the higher harmonics due to their tiny values. For the sake of convenience, in this paper, the higher order harmonics are not taken into account. Comparing Figure 7(a) with Figures 7(b)-7(d), it is shown that as SAGE happens and increases, both the DC component and the 2nd harmonic component of MPPUA will be increased. This is consistent with the previous analysis.

As illustrated in Figures $7(\mathrm{a})$ and $7(\mathrm{e})-7(\mathrm{~g})$, the occurrence and development of RISC will generally increase the 1st, $3 \mathrm{rd}$, and 4th harmonic components but meanwhile decrease the 2nd harmonic component. This can be qualitatively 


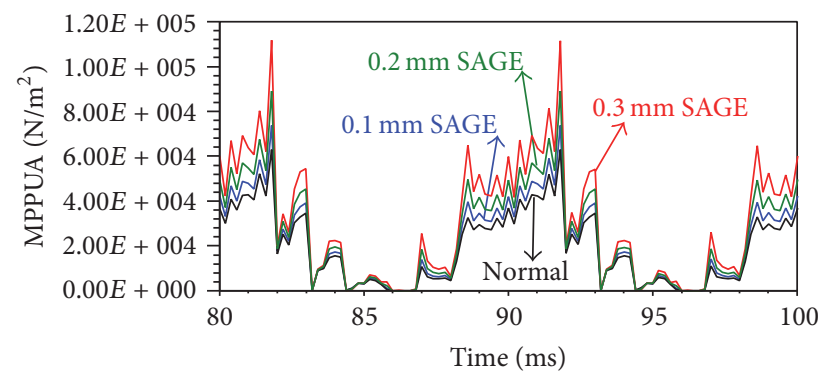

(a) MPPUA under different SAGE conditions

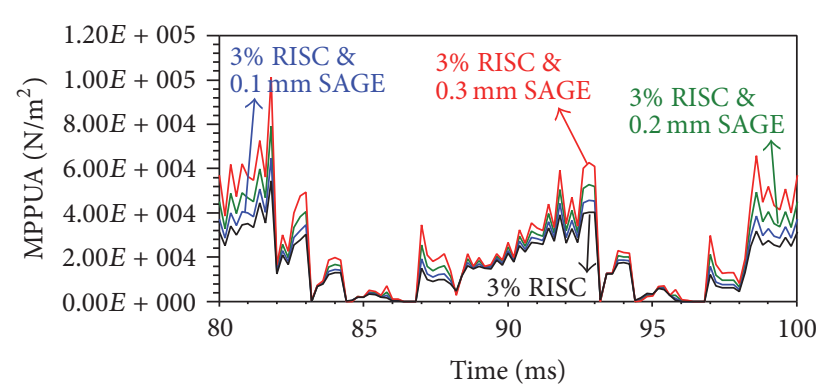

(c) MPPUA under CFs with different SAGE values

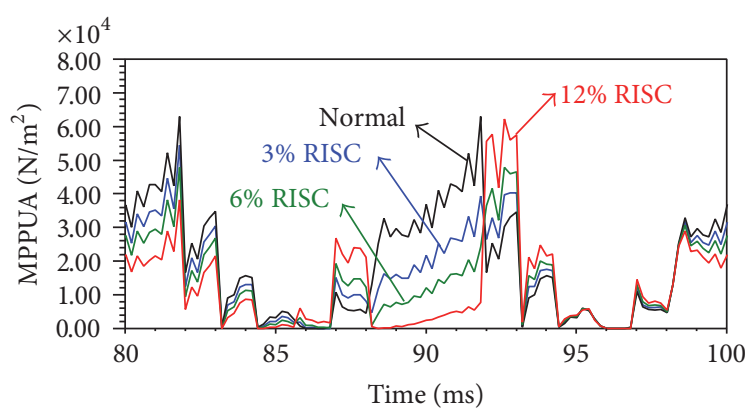

(b) MPPUA under different RISC conditions

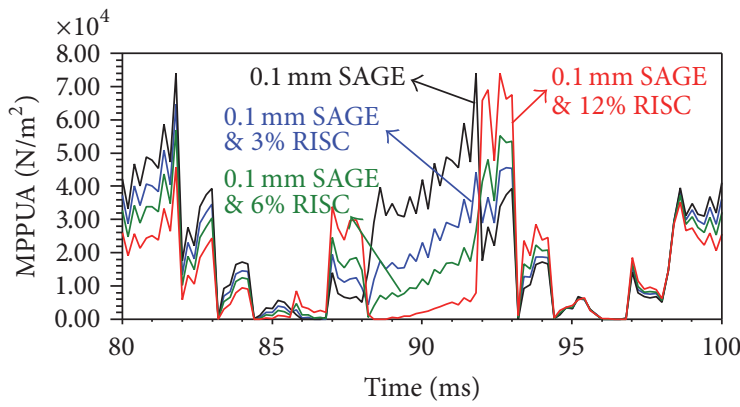

(d) MPPUA under CFs with different RISC degrees

FIGURE 5: Time domain curves of MPPUA under different conditions.

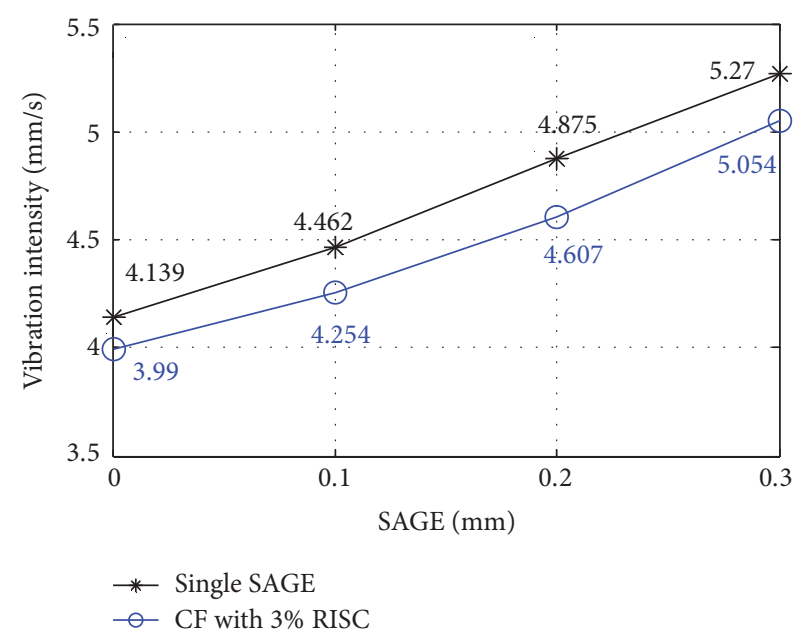

(a) Vibration intensity under different SAGE conditions

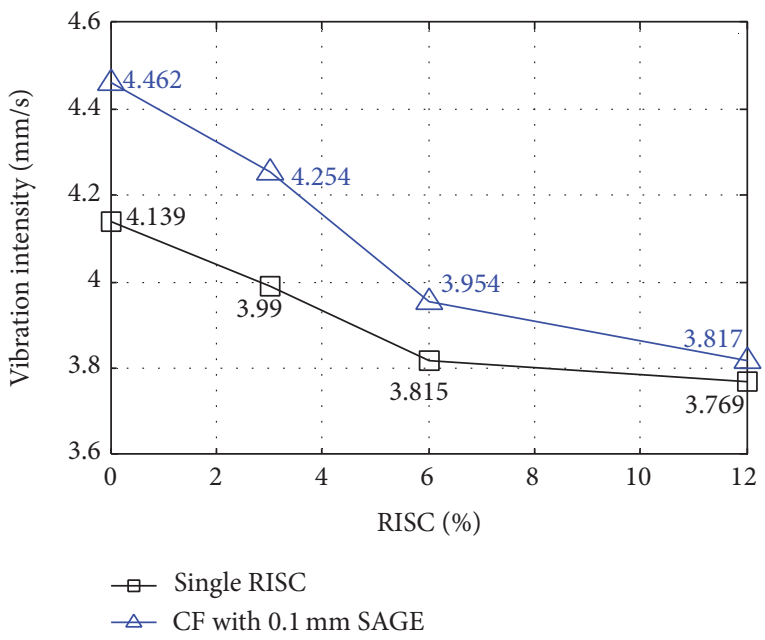

(b) Vibration intensity under different RISC conditions

FIGURE 6: Vibration intensity under different performing conditions.

explained by Table 1 . As indicated in Table 1, normally, there are no 1st, 3rd, and 4th harmonic components, while under RISC the 1st, 2nd, 3rd, and 4th harmonic components appear. Therefore, the new components brought in by RISC will be increased. Moreover, the MPPUA amplitude in normal condition is $F_{1}^{2} \Lambda_{0}^{2} / 4 \mu_{0}$, while under RISC the amplitude is $F_{C}^{2} \Lambda_{0}^{2} / 4 \mu_{0}$. As illustrated in Figures $1(\mathrm{c})$ and $1(\mathrm{~d})$, it is obvious that $F_{C}$ is smaller than $F_{1}$, resulting in the decrease of the 2 nd harmonic component of MPPUA.

Comparing Figure 7(h) with Figure 7(b), Figure 7(k) with Figure 7(c), and Figure 7(l) with Figure 7(d), it can be found that MPPUA under CF has a smaller value at $2 f$ ( $f$ is the electrical frequency) but meanwhile has a larger value at $f, 3 f$, and $4 f$ than under the single SAGE fault. This again confirms the conclusion presented in the previous paragraph that RISC will increase the 1st, 3rd, and 4th harmonic components but meanwhile decrease the 2 nd harmonic component. In addition, comparing Figure 7(h) with Figure 7(e), Figure 7(i) with Figure 7(f), and Figure 7(j) with Figure 7(g), it is shown that the 1st to the 4th harmonic components of MPPUA under CF are all larger than those under RISC. This means SAGE will generally increase MFD, which has been found out 


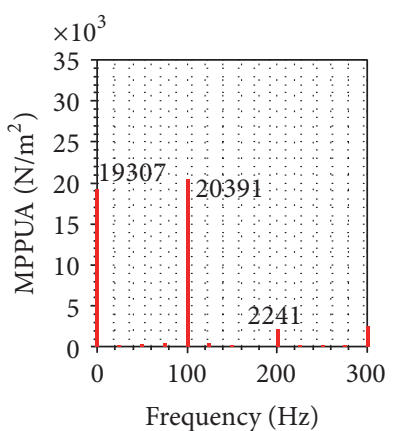

(a) Normal condition

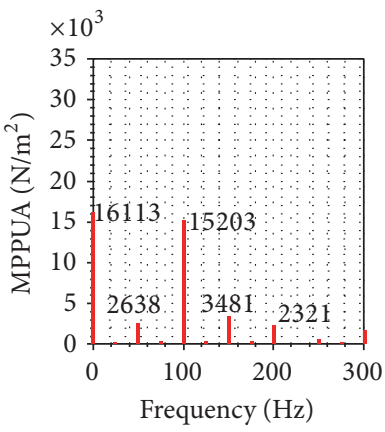

(e) $3 \%$ RISC

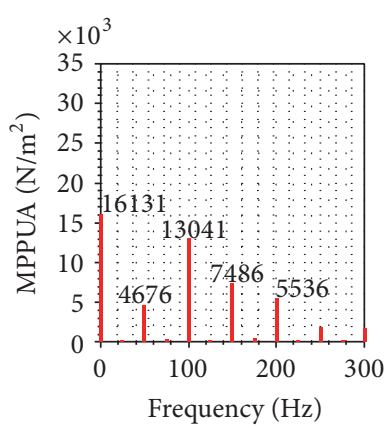

(i) $0.1 \mathrm{~mm}$ SAGE and $6 \%$ RISC

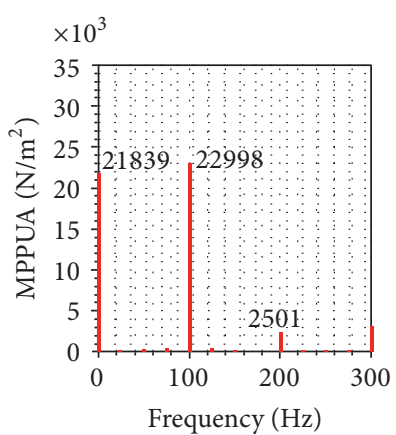

(b) $0.1 \mathrm{~mm}$ SAGE

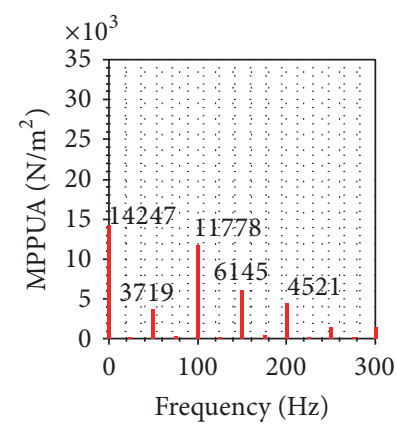

(f) $6 \%$ RISC

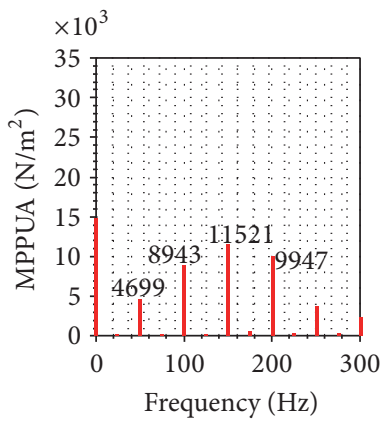

(j) $0.1 \mathrm{~mm}$ SAGE and $12 \%$ RISC

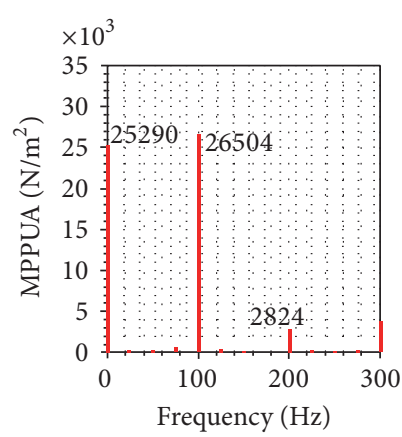

(c) $0.2 \mathrm{~mm}$ SAGE

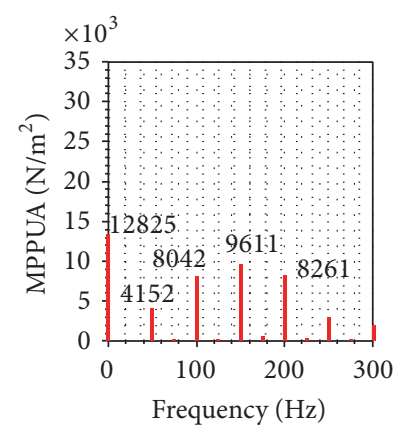

(g) $12 \%$ RISC

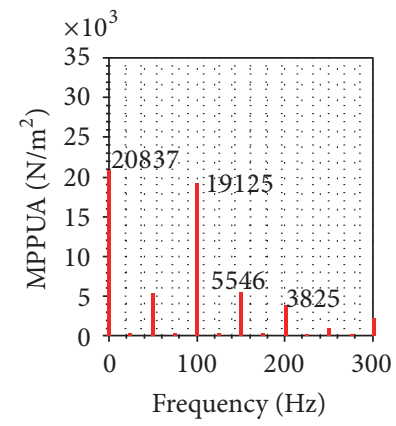

(k) $3 \%$ RISC and $0.2 \mathrm{~mm}$ SAGE

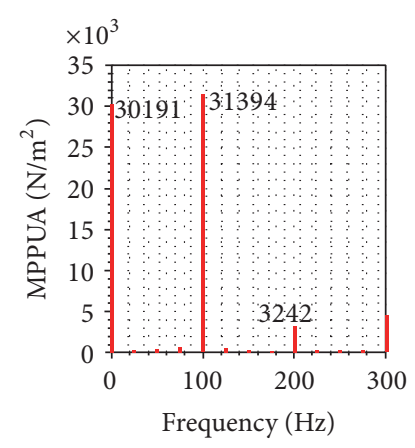

(d) $0.3 \mathrm{~mm}$ SAGE

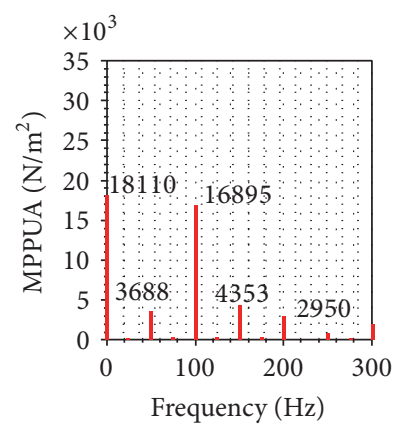

(h) $0.1 \mathrm{~mm}$ SAGE and $3 \%$ RISC

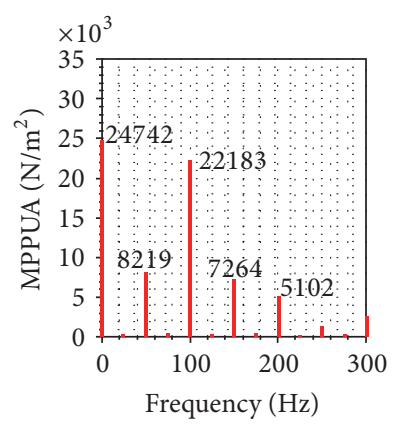

(l) $3 \%$ RISC and $0.3 \mathrm{~mm}$ SAGE

FIgURE 7: Spectra of MPPUA under different conditions.

previously. Actually, the amplitude formulas indicated in Table 1 can also explain this well, for the permeance under CF is $\left(\Lambda_{0}+\Lambda_{s}\right)$, while the permeance under RISC is only $\Lambda_{0}$ (see Table 1).

Taking MPPUA as the exciting force, the stator vibration can be treated as the response. As indicated in Figure 8, the stator vibration tendency at each harmonic frequency well follows the developing trend of MPPUA. Specifically, Figure 8(a) shows that the stator vibration in normal condition not only has each even harmonic component (primarily the 2nd and the 4th harmonics) but also includes each odd harmonic component (primarily the 1st, 3rd, and 5th harmonics). In theory, as analyzed previously, there should be only even harmonic components existing (primarily the 2 nd harmonic). The extra odd harmonic components of the stator vibration are mainly transferred from the rotor vibration (the rotor and the stator both located on the basis; see Figure 3(a)) and caused by the initial asymmetry inside the generator. To study the essential effect of each kind of fault on the stator vibration, the vibration amplitudes of each harmonic in normal condition are treated as the null drifts of the experiment system, and the faulty vibration amplitudes are subtracted by these null drifts. For example, comparing with the normal condition, vibration amplitude at $2 f$ for $0.1 \mathrm{~mm}$, $0.2 \mathrm{~mm}$, and $0.3 \mathrm{~mm}$ SAGE increases by $32.9 \%(0.886 \mathrm{~mm} / \mathrm{s})$, $50.5 \%(1.359 \mathrm{~mm} / \mathrm{s})$, and $70.9 \%(1.909 \mathrm{~mm} / \mathrm{s})$, respectively. This indicates that these increments of the vibration amplitude are the essential impact caused by the three SAGE fault conditions.

To better show the relation between the input excitation force and the output vibration response, the line charts of MPPUA and the stator vibration at each frequency under different running conditions are illustrated in Figure 9. It is shown that the developing tendency of the tested stator 
TABLE 3: Fault identification criterion based on stator vibration characteristics.

Stator vibration characteristics Performing condition

Having only soft 2nd harmonic vibrations

Normal condition

The vibration at $2 f$ is increased, while the other components generally keep stable

SAGE exists

The vibration at $2 f$ is decreased, but meanwhile vibrations at $f, 3 f$, and $4 f$ are increased

RISC exists

The vibration at $2 f$ is firstly decreased and then increased; meanwhile, vibrations at $f, 3 f$, and $4 f$ are increased

CF exists

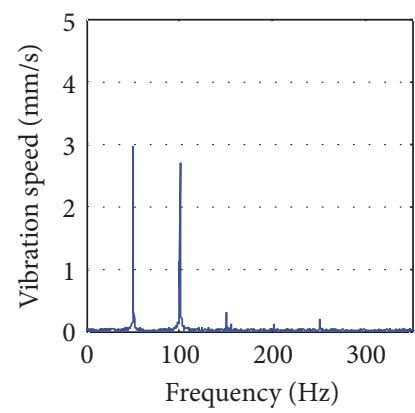

(a) Normal condition

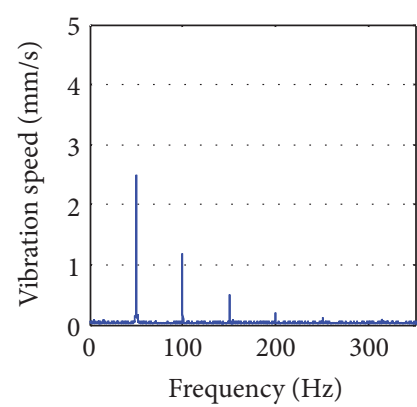

(e) $3 \%$ RISC

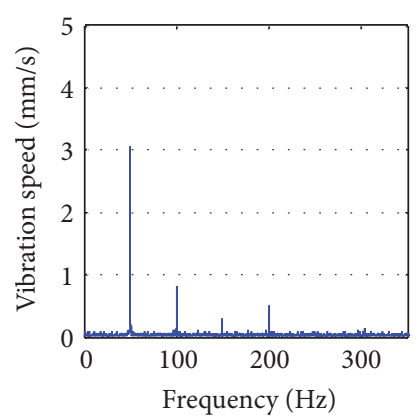

(i) $0.1 \mathrm{~mm}$ SAGE and $6 \%$ RISC

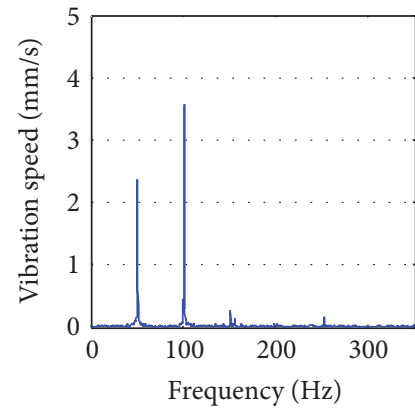

(b) $0.1 \mathrm{~mm}$ SAGE

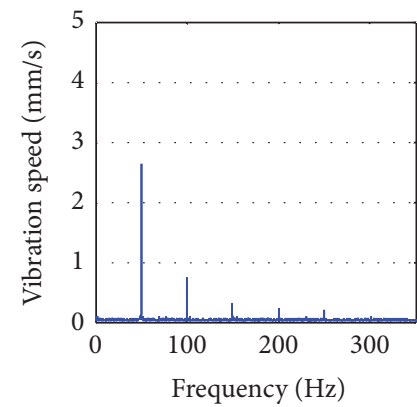

(f) $6 \%$ RISC

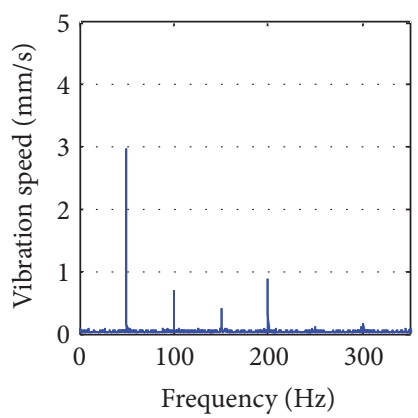

(j) $0.1 \mathrm{~mm}$ SAGE and $12 \%$ RISC

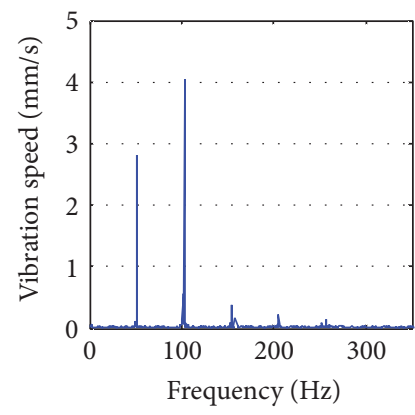

(c) $0.2 \mathrm{~mm} \mathrm{SAGE}$

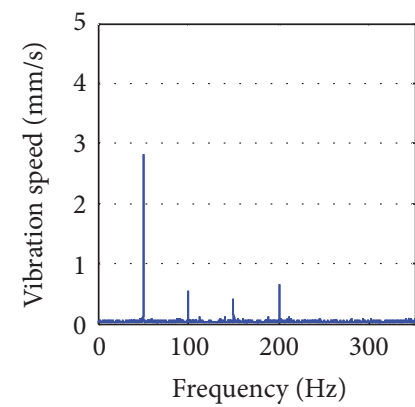

(g) $12 \%$ RISC

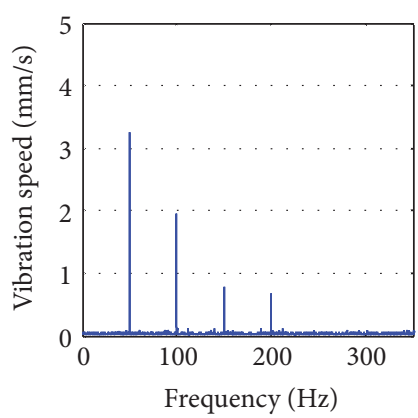

(k) $0.2 \mathrm{~mm}$ SAGE and $3 \%$ RISC

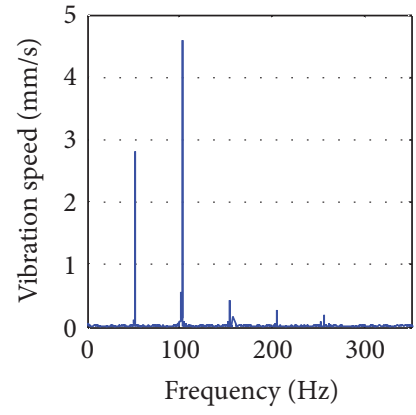

(d) $0.3 \mathrm{~mm}$ SAGE

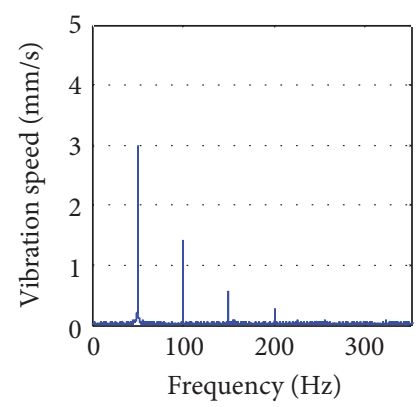

(h) $0.1 \mathrm{~mm}$ SAGE and $3 \%$ RISC

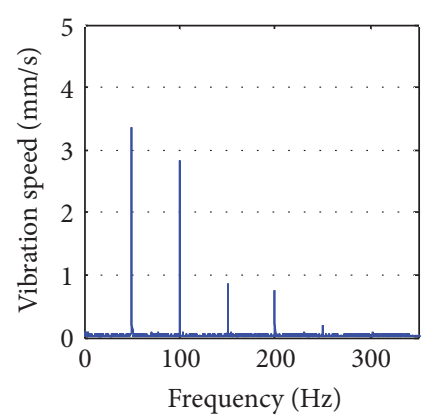

(l) $0.3 \mathrm{~mm}$ SAGE and $3 \%$ RISC

FIGURE 8: Tested stator vibration spectra under different conditions.

vibration amplitudes at each harmonic frequency generally accords with the changing trend of MPPUA. Meanwhile, it is also clear that as SAGE increases, both MPPUA and the vibration under CF have a larger value at $f, 3 f$, and $4 f$ but in the meantime have a smaller value at $2 f$ than those under the single SAGE fault. However, as RISC develops, both MPPUA and the stator vibration will have a larger value under the CF condition than under the single RISC fault. These results are in good accordance with the conclusions obtained previously, confirming that both the FEM calculation and the experiment data match the previous analysis. In addition, this also indicates that the stator vibration response is consistent with the exciting MPPUA.

3.2.3. Fault Identification Criterion. Based on the theoretical analysis, the numerical FEM calculation, and the experiment study, it is found that the stator vibration characteristic varies under different faulty conditions. This can be employed to develop an identification criterion for the single and the composite faults composed of SAGE and RISC. More details can be found in Table 3 . 


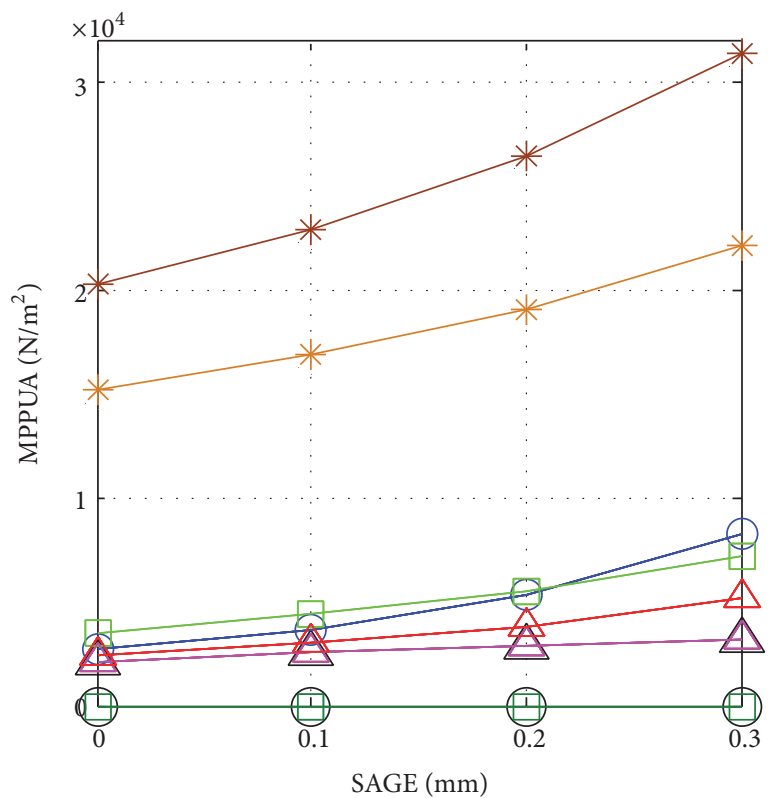

- $50 \mathrm{~Hz}$ for single fault - $50 \mathrm{~Hz}$ for $\mathrm{CF}$ * $100 \mathrm{~Hz}$ for single fault * $100 \mathrm{~Hz}$ for $\mathrm{CF}$

$$
\begin{aligned}
& \square 150 \mathrm{~Hz} \text { for single fault } \\
& \square 150 \mathrm{~Hz} \text { for } \mathrm{CF} \\
& \triangle 200 \mathrm{~Hz} \text { for single fault } \\
& \triangle 200 \mathrm{~Hz} \text { for } \mathrm{CF}
\end{aligned}
$$

(a) MPPUA when SAGE varies

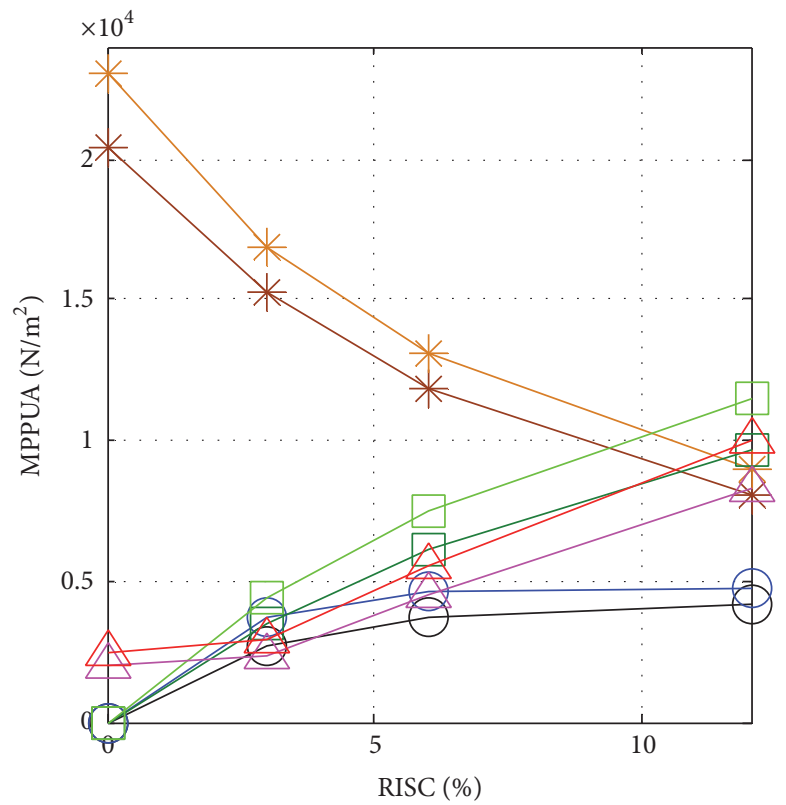

$$
\begin{array}{ll}
-550 \mathrm{~Hz} \text { for single fault } & \square 150 \mathrm{~Hz} \text { for single fault } \\
-50 \mathrm{~Hz} \text { for } \mathrm{CF} & \square 150 \mathrm{~Hz} \text { for } \mathrm{CF} \\
*-100 \mathrm{~Hz} \text { for single fault } & \triangle 200 \mathrm{~Hz} \text { for single fault } \\
*-100 \mathrm{~Hz} \text { for } \mathrm{CF} & \triangle 200 \mathrm{~Hz} \text { for } \mathrm{CF}
\end{array}
$$

(c) MPPUA when RISC develops

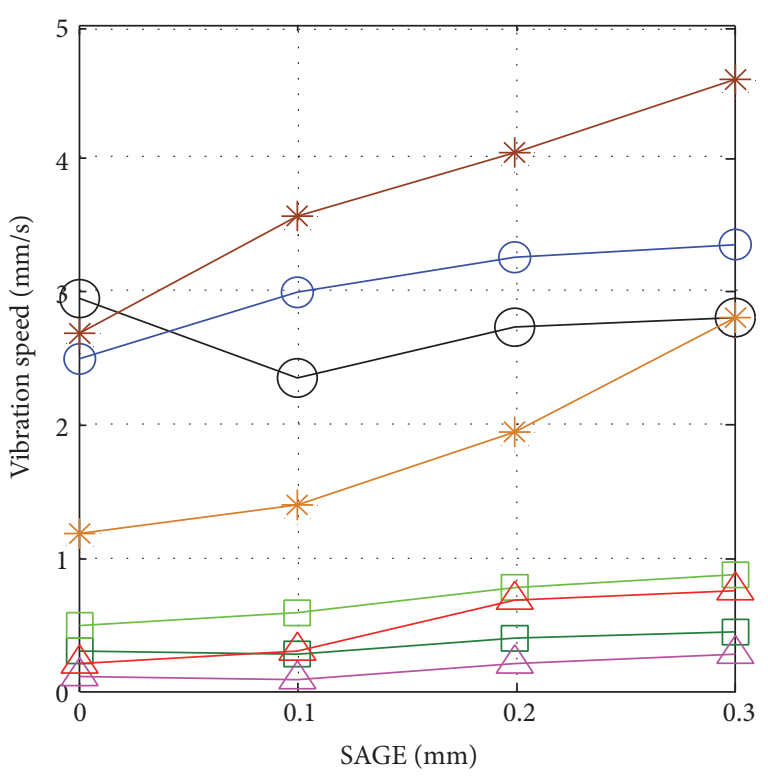

$$
\begin{array}{ll}
-50 \mathrm{~Hz} \text { for single fault } & \square 150 \mathrm{~Hz} \text { for single fault } \\
-50 \mathrm{~Hz} \text { for } \mathrm{CF} & \square 150 \mathrm{~Hz} \text { for CF } \\
* 100 \mathrm{~Hz} \text { for single fault } & \triangle 200 \mathrm{~Hz} \text { for single fault } \\
*-100 \mathrm{~Hz} \text { for } \mathrm{CF} & \triangle 200 \mathrm{~Hz} \text { for } \mathrm{CF}
\end{array}
$$

(b) Vibration when SAGE varies

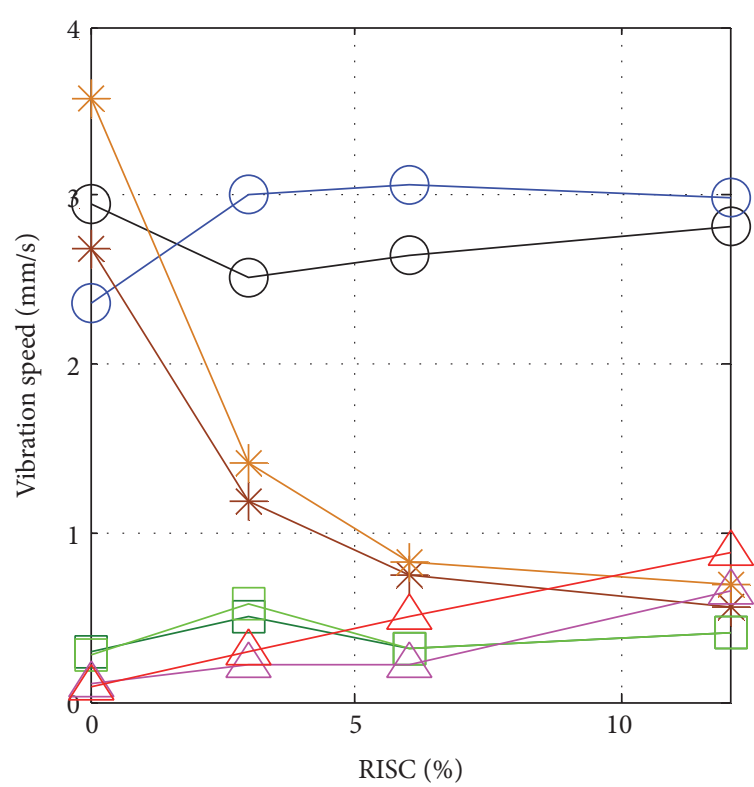

$-50 \mathrm{~Hz}$ for single fault
$-50 \mathrm{~Hz}$ for $\mathrm{CF}$
$* 100 \mathrm{~Hz}$ for single fault
$*-100 \mathrm{~Hz}$ for $\mathrm{CF}$

$\square 150 \mathrm{~Hz}$ for single fault $\square 150 \mathrm{~Hz}$ for $\mathrm{CF}$

$\triangle 200 \mathrm{~Hz}$ for single fault

$\triangle 200 \mathrm{~Hz}$ for $\mathrm{CF}$

(d) Vibration when RISC develops

FIGURE 9: Comparison between MPPUA and tested stator vibration for different conditions. 


\section{Conclusions}

This paper investigates the stator vibration difference among SAGE, RISC, and the composite faults composed of SAGE and RISC. Based on the proposed theoretical analysis, the numerical FEM calculation, and the experimental study, primary conclusions can be generally drawn as follows:

(1) Normally, stator vibration has only the 2nd harmonic component in theory, while actually it also has the 1st harmonic component which is transferred from the rotor vibration. The occurrence of SAGE will increase the 2nd harmonic component.

(2) As RISC and CF take place in the generator, extra stator vibrations at $f, 2 f, 3 f$, and $4 f$ will be produced. As RISC develops, the 1st, 3rd, and the 4th harmonic components will be increased, while the 2nd harmonic component will be decreased.

(3) In the case of CF, the increment of SAGE will raise the 1st, 2nd, 3rd, and the 4th harmonic components of the stator vibration at the same time, while under the single SAGE fault only the 2nd harmonic component will be increased.

(4) As RISC develops, the stator vibration under CF at $f$, $2 f, 3 f$, and $4 f$ will have a larger intensity than under the single RISC fault. However, as SAGE increases, the stator vibration under $\mathrm{CF}$ will be more intensive at $f$, $3 f$, and $4 f$ but meanwhile have weaker amplitude at $2 f$ than under the single SAGE fault.

Potentially, these sensitive conclusions can be applied to the practical online monitoring on the generators. Since it is very convenient to test the stator vibration with the industrial velocity sensors, further development of monitoring systems and utilities, which will be beneficial for the fault identification among SAGE, RISC, and the composite fault composed of SAGE and RISC, is probably to be carried out.

\section{Competing Interests}

The authors declare that they have no competing interests.

\section{Acknowledgments}

This work is supported by the National Natural Science Foundation of China (51307058), the Natural Science Foundation of Hebei Province, China (E2015502013, E2015502008), and the Chinese Fundamental Research Funds for the Central Universities (2015ZD27).

\section{References}

[1] C. Bruzzese, "Diagnosis of eccentric rotor in synchronous machines by analysis of split-phase currents-part II: experimental analysis," IEEE Transactions on Industrial Electronics, vol. 61, no. 8, pp. 4206-4216, 2014.

[2] W. Yucai and L. Yonggang, "Diagnosis of rotor winding interturn short-circuit in turbine generators using virtual power,"
IEEE Transactions on Energy Conversion, vol. 30, no. 1, pp. 183$188,2015$.

[3] C. Bruzzese and G. Joksimovic, "Harmonic signatures of static eccentricities in the stator voltages and in the rotor current of no-load salient-pole synchronous generators," IEEE Transactions on Industrial Electronics, vol. 58, no. 5, pp. 1606-1624, 2011.

[4] M. Blödt, J. Regnier, and J. Faucher, "Distinguishing load torque oscillations and eccentricity faults in induction motors using stator current wigner distributions," IEEE Transactions on Industry Applications, vol. 45, no. 6, pp. 1991-2000, 2009.

[5] C. Bruzzese, "Diagnosis of eccentric rotor in synchronous machines by analysis of split-phase currents-part II: experimental analysis," IEEE Transactions on Industrial Electronics, vol. 61, no. 8, pp. 4206-4216, 2014.

[6] X. Y. Zhao and W. T. Ge, "Simulation research of fault model of detecting rotor dynamic eccentricity in brushless DC motor based on motor current signature analysis," Proceedings of the Chinese Society of Electrical Engineering, vol. 31, no. 36, pp. 124130, 2011.

[7] S. Yuguang, H. Liangliang, and W. Xiangheng, "Steady-state currents harmonic characteristics of synchronous machine with inter-turn short circuits of field windings," Proceedings of the CSEE, vol. 33, no. 33, pp. 51-57, 2010.

[8] J. Li and Y. Cho, "Dynamic reduction of unbalanced magnetic force and vibration in switched reluctance motor by the parallel paths in windings," Mathematics and Computers in Simulation, vol. 81, no. 2, pp. 407-419, 2010.

[9] Y.-L. He, G.-J. Tang, S.-T. Wan, and Y.-C. Wu, "Effect of the static air-gap eccentricity \& stator inter-turn short circuit composite fault on the generator circulating current characteristics," International Review of Electrical Engineering, vol. 7, no. 5, pp. 54425450, 2012.

[10] D. Žarko, D. Ban, I. Vazdar, and V. Jaríc, "Calculation of unbalanced magnetic pull in a salient-pole synchronous generator using finite-element method and measured shaft orbit," IEEE Transactions on Industrial Electronics, vol. 59, no. 6, pp. 2536$2549,2012$.

[11] L. J. Wu, Z. Q. Zhu, J. T. Chen, and Z. P. Xia, "An analytical model of unbalanced magnetic force in fractional-slot surfacemounted permanent magnet machines," IEEE Transactions on Magnetics, vol. 46, no. 7, pp. 2686-2700, 2010.

[12] S. Nadarajan, S. K. Panda, B. Bhangu, and A. K. Gupta, "Hybrid model for wound-rotor synchronous generator to detect and diagnose turn-to-turn short-circuit fault in stator windings," IEEE Transactions on Industrial Electronics, vol. 62, no. 3, pp. 1888-1900, 2015.

[13] D. Shah, S. Nandi, and P. Neti, "Stator-interturn-fault detection of doubly fed induction generators using rotor-current and search-coil-voltage signature analysis," IEEE Transactions on Industry Applications, vol. 45, no. 5, pp. 1831-1842, 2009.

[14] H.-M. Li, Y.-C. Wu, and Y.-G. Li, "Influence of rotor windings inter-turn short circuit fault on electric machine shaft voltage," Proceedings of the Chinese Society of Electrical Engineering, vol. 29, no. 36, pp. 96-100, 2009.

[15] Y. C. Wu, Y. G. Li, and H. M. Li, "Diagnosis of non-salient pole synchronous generator rotor's typical faults based on shaft voltage," Transactions of China Electrotechnical Society, vol. 25, no. 6, pp. 178-184, 2010.

[16] L. Yong-gang, Z. Yan-jun, C. Lei, and J. Xuan, "Rotor winding inter-turn short circuit fault diagnosis based on the circulating current in stator winding parallel branches," High Voltage Engineering, vol. 35, no. 5, pp. 1014-1019, 2009. 
[17] J. G. Cintron-Rivera, S. N. Foste, and E. G. Strangas, "Mitigation of turn-to-turn faults in fault tolerant permanent magnet synchronous motors," IEEE Transactions on Energy Conversion, vol. 30, no. 2, pp. 465-475, 2015.

[18] Y.-C. Wu, Y.-G. Li, W.-Z. Feng, and W.-J. Zhang, "Analysis on unbalanced magnetic pull generated by turn-to-turn short circuit of rotor windings within turbine generator," Electric Machines and Control, vol. 19, no. 3, pp. 37-44, 2015.

[19] L. Hao, J. Wu, and Y. Zhou, "Theoretical analysis and calculation model of the electromagnetic torque of nonsalient-pole synchronous machines with interturn short circuit in field windings," IEEE Transactions on Energy Conversion, vol. 30, no. 1, pp. 110-121, 2015.

[20] Y.-L. He, F.-L. Wang, M.-Q. Ke, and G.-J. Tang, "Rotor vibration difference among the single and the combined faults composed by static air-gap eccentricity and rotor interturn short circuit," in Proceedings of the 9th IFToMM International Conference on Rotor Dynamics, vol. 21 of Mechanisms and Machine Science, pp. 637-648, 2015.

[21] L. Hao, J. Wu, Z. Chen, and H. Song, "Mechanism of effects of inter-turn short circuits in field windings on large turbogenerator vibration," Automation of Electric Power Systems, vol. 38, no. 4, pp. 25-50, 2014.

[22] H.-W. Fang, C.-L. Xia, and G.-P. Li, "Analysis of synchronous generator electro-magnetic torque and vibration with armature winding fault," Journal of Tianjin University, vol. 42, no. 4, pp. 322-326, 2009.

[23] P. C. M. Lamim Filho, R. Pederiva, and J. N. Brito, "Detection of stator winding faults in induction machines using flux and vibration analysis," Mechanical Systems and Signal Processing, vol. 42, no. 1-2, pp. 377-387, 2014.

[24] Y.-L. He, M.-Q. Ke, F.-L. Wang, G.-J. Tang, and S.-T. Wan, "Effect of static eccentricity and stator inter-turn short circuit composite fault on rotor vibration characteristics of generator," Transactions of the Canadian Society for Mechanical Engineering, vol. 39, no. 4, pp. 767-781, 2015. 


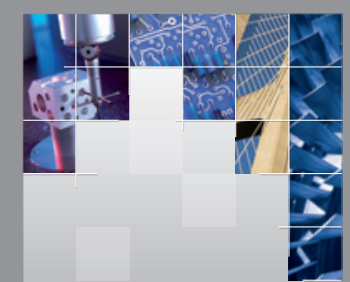

\section{Enfincering}
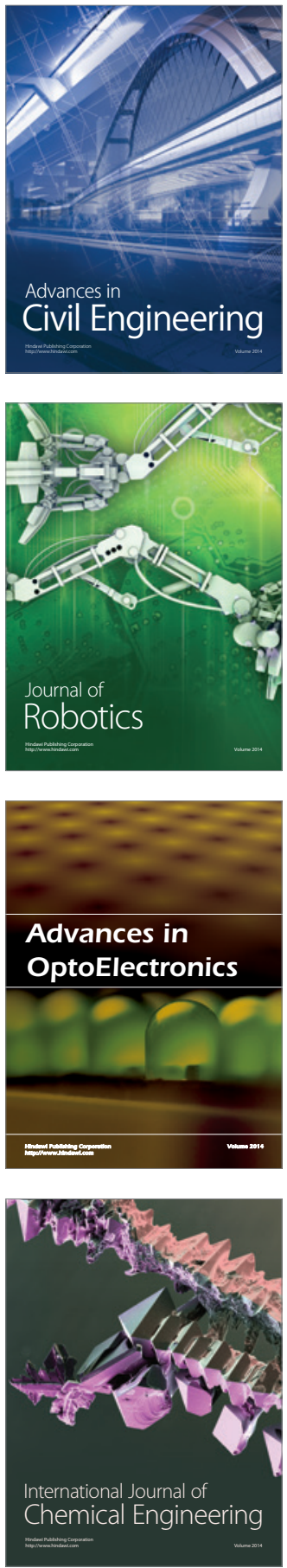

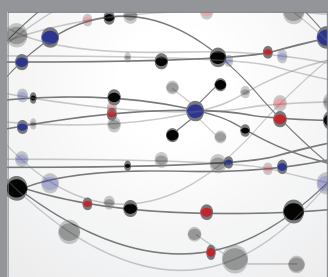

The Scientific World Journal

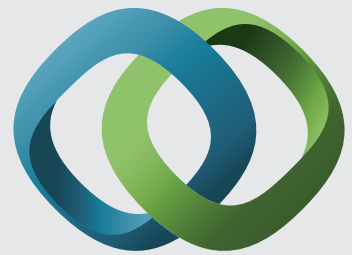

\section{Hindawi}

Submit your manuscripts at

http://www.hindawi.com
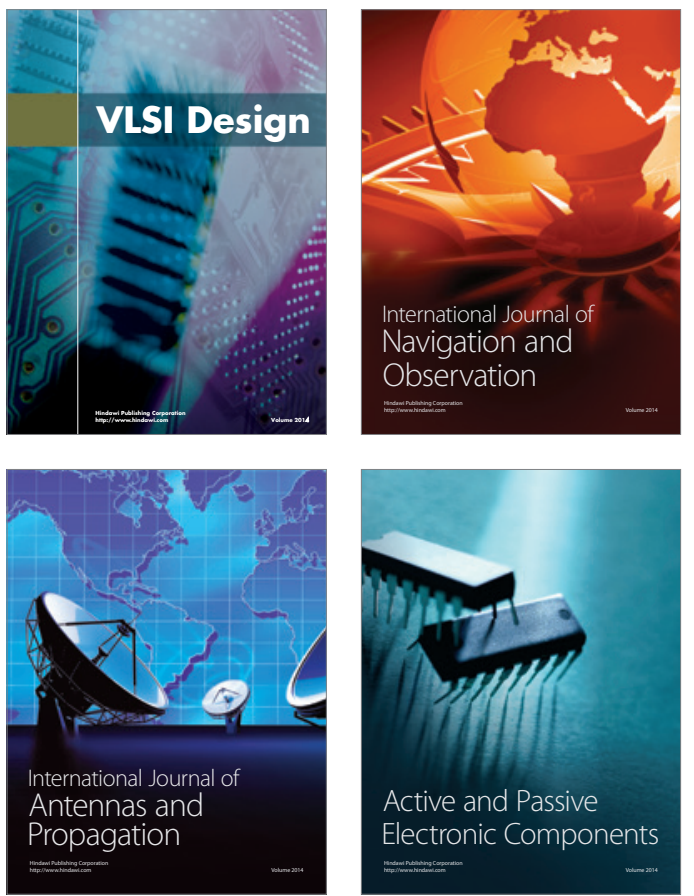
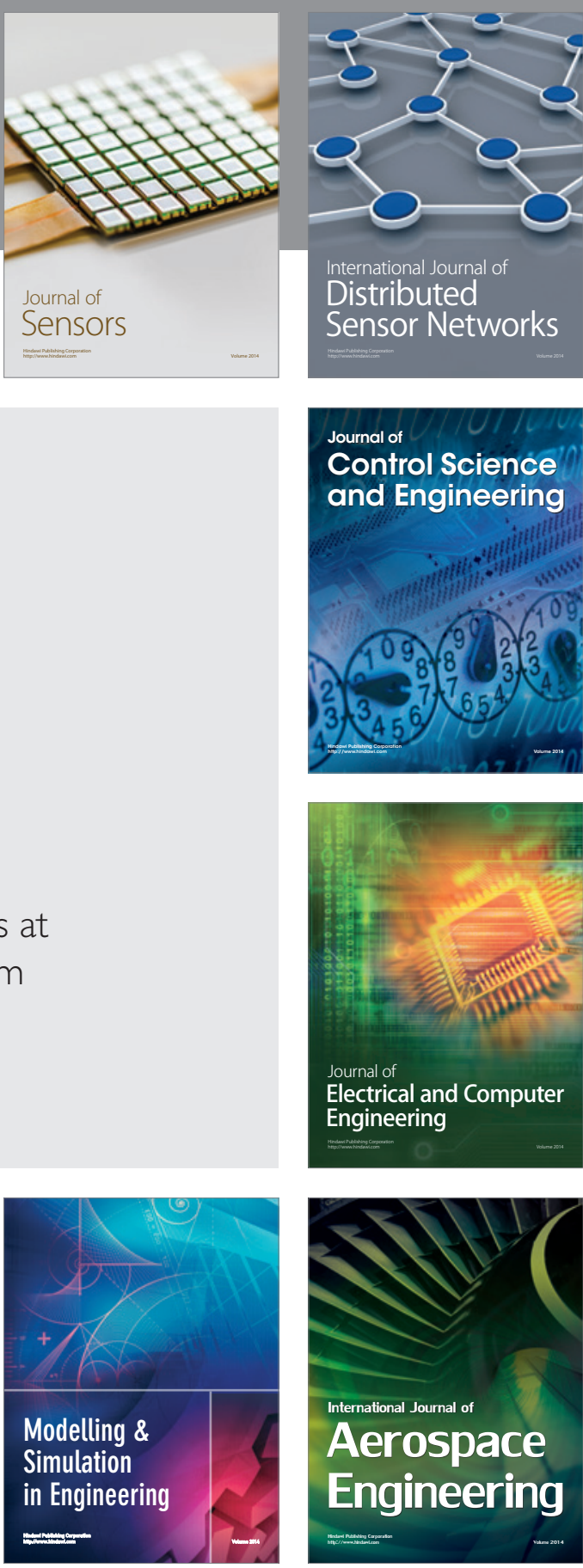

International Journal of

Distributed

Sensor Networks

Journal of

Control Science

and Engineering
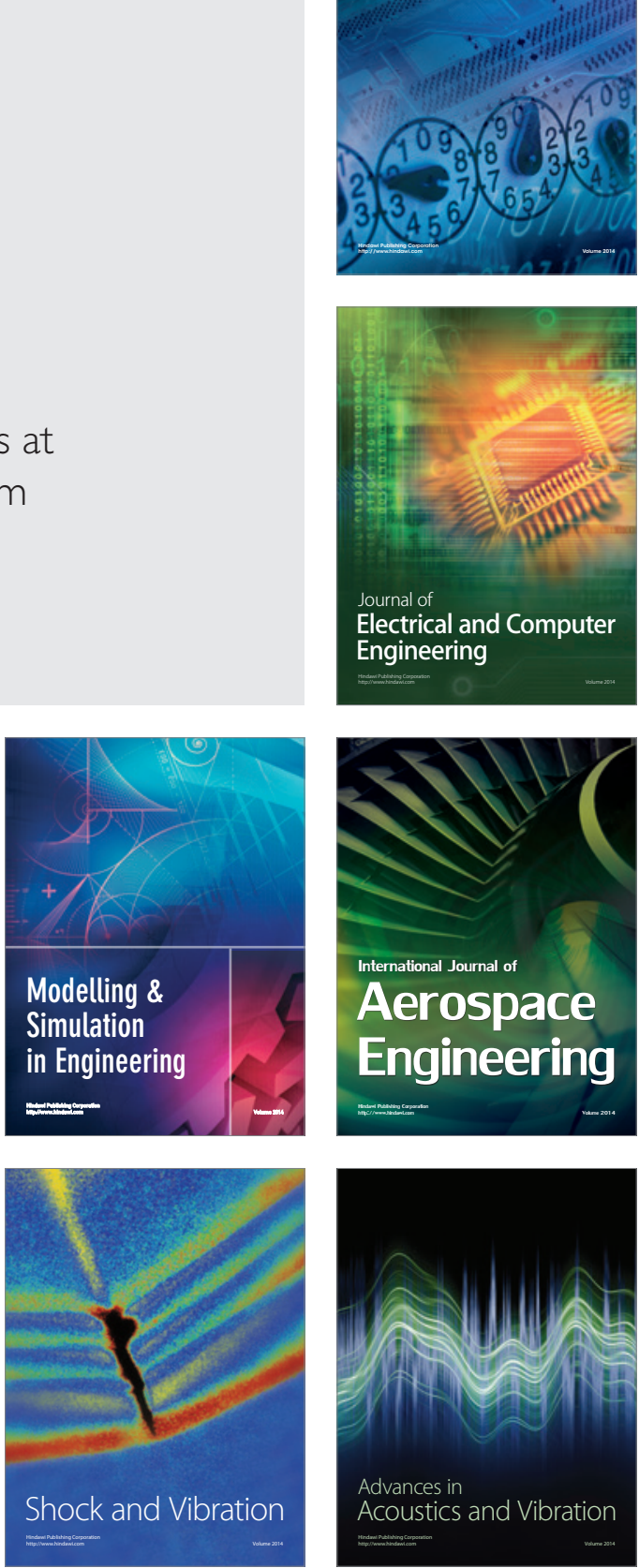